\title{
¿ES REALMENTE VIABLE EL CONTROL DE CONVENCIONALIDAD?
}

\section{IS THE CONTROL OF CONVENTIONALITY REALLY VIABLE?}

\author{
Max Silva Aвbotт*
}

\begin{abstract}
RESUMEN: La manera teórica en que la doctrina mayoritaria aborda el control de convencionalidad, podría verse notablemente modificada si se toma en cuenta el real nivel de cumplimiento que han tenido las sentencias en que la Corte Interamericana ha ordenado llevarlo a cabo. El presente trabajo analiza este dato, casi siempre omitido, y lo incorpora a la doctrina del control de convencionalidad, para intentar determinar si dicho control resulta viable en la práctica. Lo anterior, dado el papel protagónico que se le asigna a la Corte para su correcto funcionamiento.
\end{abstract}

Palabras clave: Control de convencionalidad; cumplimiento de las sentencias de la Corte Interamericana; supervisiones de cumplimiento; efectos inter partes; efectos erga omnes.

ABSTRACT: The theoretical way in which the majority doctrine addresses the control of conventionality, could be significantly modified if one takes into account the real level of compliance with the judgments in which the Inter-American Court has ordered to carry out. The present work analyzes this data, almost always omitted, and incorporates it into the doctrine of conventionality control, to try to determine if such control is viable in practice. The above, given the leading role assigned to the Court for its proper functioning.

Keywords: Control of conventionality; compliance with the judgments of the Inter-American Court; monitoring compliance; inter partes effect; erga omnes effect.

\section{INTRODUCCIÓN}

Actualmente existe lo que podría llamarse un planteamiento 'oficial' de la teoría del control de convencionalidad, que es impulsado tanto por la jurisprudencia de la Corte Interamericana como por la doctrina mayoritaria, que ha sido ampliamente difundido. Sin embargo, el presente trabajo indaga en un dato que por regla general ha sido omitido a su respecto: el real nivel de cumplimiento que han tenido los fallos que establecen dicho control, varios de los cuales son paradigmáticos al momento de fundamentarlo. De ahí que resulte lícito preguntarse por un lado si la manera de plantear el control de convencionalidad sería diferente si se tomara en cuenta este dato y por otro y como consecuencia de lo anterior, hasta qué punto resulta viable, dado el papel protagónico que se le asigna a la Corte para su correcto funcionamiento.

Para intentar responder a estas preguntas, primero se pasará revista brevemente y sin polemizar con él, al actual estado teórico del control de convencionalidad, tal como es

* Doctor en Derecho por la Universidad de Navarra. Profesor de Filosofía del Derecho de la Facultad de Derecho, Universidad San Sebastián, sede Concepción. Dirección Postal: Lientur 1457, Concepción. Dirección electrónica: max.silva@uss.cl. 
presentado por la doctrina mayoritaria. Si bien lo anterior resulta por regla general bastante conocido, resulta indispensable traerlo a colación, para tener claridad sobre las reales implicancias que para dicha teoría tiene el nivel de cumplimiento aludido. Luego se explicará la metodología empleada para el análisis y la clasificación de la eficacia que han tenido las sentencias en que la Corte ha ordenado llevar a cabo dicho control, cuyos datos constan en los anexos I y II de este trabajo. Posteriormente se mostrarán estos datos mediante gráficos y se harán algunos breves comentarios a su respecto. Más tarde, y sobre la base de la descripción teórica precedente, se procederá a replantear la doctrina del control de convencionalidad incorporando esta nueva información y como se ha dicho, se intentará determinar si dicho control resulta viable. Finalmente se arribará a algunas conclusiones.

\section{LOS ASPECTOS MÁS RELEVANTES DE LA DOCTRINA DEL CONTROL DE CONVENCIONALIDAD}

En el presente apartado se expondrán, sin profundizar en ellas, las principales afirmaciones que realizan la jurisprudencia de la Corte Interamericana y la doctrina dominante acerca del control de convencionalidad, asumiendo, además, una mirada acrítica y planteándolas de manera hipotética (esto es, con todas las consecuencias que se le asignan), a fin de dejar en claro tanto sus alcances teóricos como el rol que se le otorga a este tribunal para su correcta aplicación. Lo anterior, a fin de tener un claro punto de referencia al cual añadir posteriormente la información práctica que se analiza en este trabajo.

Como se sabe, el control de convencionalidad no está contemplado en la Convención Americana ${ }^{1}$, sino que ha sido desarrollado por vía jurisprudencial, siendo establecido por primera vez en el caso ALMONACID ARELLANO Y OTROS vS CHILE ${ }^{2}$.

Sin embargo, suele distinguirse entre un control de convencionalidad externo, que realiza la Corte ${ }^{3}$ y otro interno, que es el que estarían llamados a hacer los jueces locales . $^{4}$

El control de convencionalidad ha experimentado una constante ampliación ${ }^{5}$, si bien su desarrollo jurisprudencial no ha sido siempre lineal ni orgánico ${ }^{6}$. Así, luego de consagrarlo en el caso ALMONACID, la Corte estimó que debía ser hecho por los jueces del Poder Judicial de oficio y "evidenetemente dentro del marco de sus respectivas competencias y

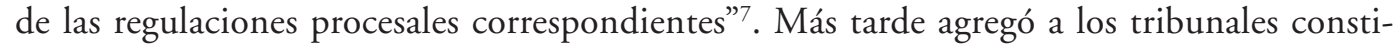
tucionales ${ }^{8}$; luego le llegó el turno a todas las autoridades locales, lo que comprende a los

\footnotetext{
García (2011) pp. 144-145; Castilla (2013) p. 53; Dulitzky (2015) pp. 50-52 y 54-55.

Almonacid ARellano y otros vs Chile (2006) párr. 123-125.

Castilla (2014) pp. 167-168; Nogueira (2012b) pp. 1167-1168; Sagüés (s/f b) p. 382.

García (2011) pp. 123-159; BazÁn (2012) pp. 24 y 31; Caballero (2011) pp. 119-129.

Hitters (2008) p. 147; García y Contreras (2014) pp. 217-218; Henríquez (2014) pp. 123 y 131.

Castilla (2016) pp. 87-125; Mejía (2014) pp. 121-138; Contesse (2013) pp. 5-6.

Desde Trabajadores Cesados del Congreso (Aguado Alfaro y otros) vs Perú (2006) párr. 128, en la gran mayoría de los fallos en que se alude a este tema.

8 Por ejemplo, en Cabrera García y Montiel Flores vs México (2010) párr. 225; Gelman vs Uruguay (2011) párr. 193; GELMAN vS URUGUAY. Supervisión de cumplimiento de sentencia (2013) párr. 66, 68-69, 7172, 73-78, 80-87, 89 y 102. Comentan esto BAZÁn (2012) pp. 36-43; NogueIra (2012b) pp. 1184, 1204-1217 y 1219; SAGÜÉs (2009) p. 2.
} 
poderes Ejecutivo y Legislativo ${ }^{9}$ y finalmente, se aplicó también a las instancias democráti$\operatorname{cas}^{10}$. Es por eso por lo que se señalaba en su momento que el control de convencionalidad era una especie de "rayo exterminador de normas locales"11. Aquí trataremos fundamentalmente el que se llama a realizar a los jueces domésticos.

Además, debe tenerse presente que el punto de referencia para llevarlo a cabo es el denominado "material normativo controlante", que comprende tanto la Convención Americana y los demás tratados del Sistema Interamericano, como la jurisprudencia de la Corte a su respecto ${ }^{12}$.

Ahora bien, volviendo al control que se insta a realizar los jueces internos, se ha dicho que estos debieran intentar primero una armonización entre ambos órdenes normativos $^{13}$ (lo que se llama también "interpretación conforme") y solo en el evento de resultar incompatibles, estarían obligados a dejar de lado o inaplicar la normativa local ${ }^{14}$, incluso si es de rango constitucional, en pos de la disposición internacional.

En caso de no terminar con la inconvencionalidad, el país caería en responsabilidad internacional ${ }^{15}$, pues se estima que ella continúa mientras subsista la norma incompatible ${ }^{16}$.

Con todo, la anterior posibilidad sufre una excepción, en caso de que las disposiciones internas sean más favorables que las internacionales, en virtud del principio pro homine, que obliga a buscar la normativa que más proteja o que menos restrinja los derechos en juego ${ }^{17}$.

Por eso, si bien existen muchas definiciones y formas de explicarlo, podríamos decir que el control de convencionalidad es la comparación que la Corte Interamericana realiza por sí misma y que también ordena hacer a los jueces nacionales, entre la Convención Americana y los demás tratados de derechos humanos del sistema interamericano que le otorgan competencia, tal como son interpretados por ella, y las normas internas de cada país, a fin de hacer primar las disposiciones internacionales sobre las nacionales, a menos

Por ejemplo, en MASACRES de EL MOZOTE Y LUGARES ALEDAÑos vS EL SALVADOR (2012) párr. 318; MENDOZA Y otros vs ARgentina (2013) párr. 323; RochaC HernáNDEZ Y Otros vs EL SALVAdor (2014) párr. 213; Comentan esto Ferrer (2014) p. 238; Nogueira (2012c) pp. 85, 93-94, 102-103 y 128.

10 GELMAN VS URUGUAY (2011) párr. 238-240; GELMAN vS URUGUAY. Supervisión de cumplimiento de sentencia (2013) párr. 69 (y nota 48). Comentan esto Henríquez (2014) p. 123; Nash (2013) pp. 498-499; Aguilar (2016a) pp. 337-365.

11 SAGÜÉs (2010) p. 130.

12 Nogueira (2012b) pp. 1181-1182; Sagüés (2009) p. 3; SagÜés (s/f a) pp. 458-461.

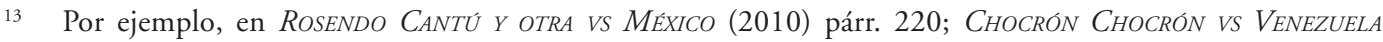
(2011) párr. 172; MASACRES de RÍo NeGRo Y Gudiel Álvarez Y Otros. Supervisión de Cumplimiento de Sentencia (2014) párr. 16. Comentan esto Caballero (2011) pp. 109-112 y 120-122; Contreras (2014) pp. $237-$ 238, 254, 261 y 263; SAGÜÉs (2003) pp. 215-216.

14 Por ejemplo, en Almonacid Arellano y otros vs Chile (2006) párr. 124; La CANTUta vs Perú (2006) párr. 173; Gomes Lund y Otros ("Guerrilha do Araguaia”) vs Brasil. Supervisión de Cumplimiento de Sentencia (2014) párr. 16 y 18. Comentan esto Nogueira (2013b) pp. 546-547; Sagưés (2010) pp. 127-128; García y Contreras (2014) pp. 217-218.

15 BazÁn (2010) pp. 170-173; Henríquez (2009) pp. 52-55; NúNÉz (2010) pp. 452-457 y $461-464$.

16 Hitters (2009) pp. 118 y 125; Mejía (2014) p. 124; Ferrer (2013) p. 666.

17 Hitters (2013) pp. 708-709; CANÇAdo (2006) pp. 310-314; Ferrer (2013) p. 676. 
que desde su perspectiva, estas últimas protejan mejor los derechos humanos que aquellas, en virtud del principio pro homine.

Sin embargo, el desarrollo jurisprudencial del control de convencionalidad ha llegado más lejos. En efecto, ya que la Corte se considera la intérprete definitiva ${ }^{18}$ e inapelable ${ }^{19}$ de la Convención, en el fondo este tratado solo 'habla' a través suyo. Por eso estima que cada interpretación que hace de la misma la va actualizando y automáticamente se incorporaría a ella. Y como los países suscribieron este tratado soberanamente, a su juicio quedarían todos obligados por dicha interpretación, aunque no hayan sido parte del litigio que le diera origen. Por tanto, el raciocinio elaborado por la Corte en cada causa (la llamada res interpretata) obligaría a todos los Estados, teniendo por ello un efecto erga omnes ${ }^{20}$. En consecuencia -continúa esta corriente-, los jueces nacionales debieran utilizar el control de convencionalidad inspirados en cualquier sentencia u opinión consultiva que dicte la Corte "para todas las hipótesis en que venga al caso su aplicación"21, y no solo en las causas que han afectado a su país ${ }^{22}$.

De esta manera, la idea es que los jueces domésticos se conviertan en los primeros guardianes de la Convención ${ }^{23}$ (algunos los llaman incluso "jueces interamericanos"24), a fin de dar verdadera eficacia al Derecho Internacional de los Derechos Humanos en nuestra región, y permitir que el Estado sea quien resuelva primero las posibles violaciones al mismo, para que el papel de la Corte sea realmente subsidiario ${ }^{25}$.

En consecuencia, la Corte pretende lograr un efecto multiplicador ${ }^{26}$ de sus fallos para todo el continente, a fin de evitar que muchos litigios lleguen a su conocimiento ${ }^{27}$, dar unidad a nuestro sistema regional de derechos humanos ${ }^{28}$ y lograr así un "orden público interamericano" ${ }^{29}$ o un "ius commune interamericano" 30 . O si se prefiere, busca convertirse en una especie de tribunal constitucional o de casación continental ${ }^{31}$ que establezca por medio de su jurisprudencia, un sistema de precedentes vinculantes ${ }^{32}$.

Esto último es muy importante, puesto que según se mencionará en más de una oportunidad, no basta con que los tribunales locales apliquen el control de convenciona-

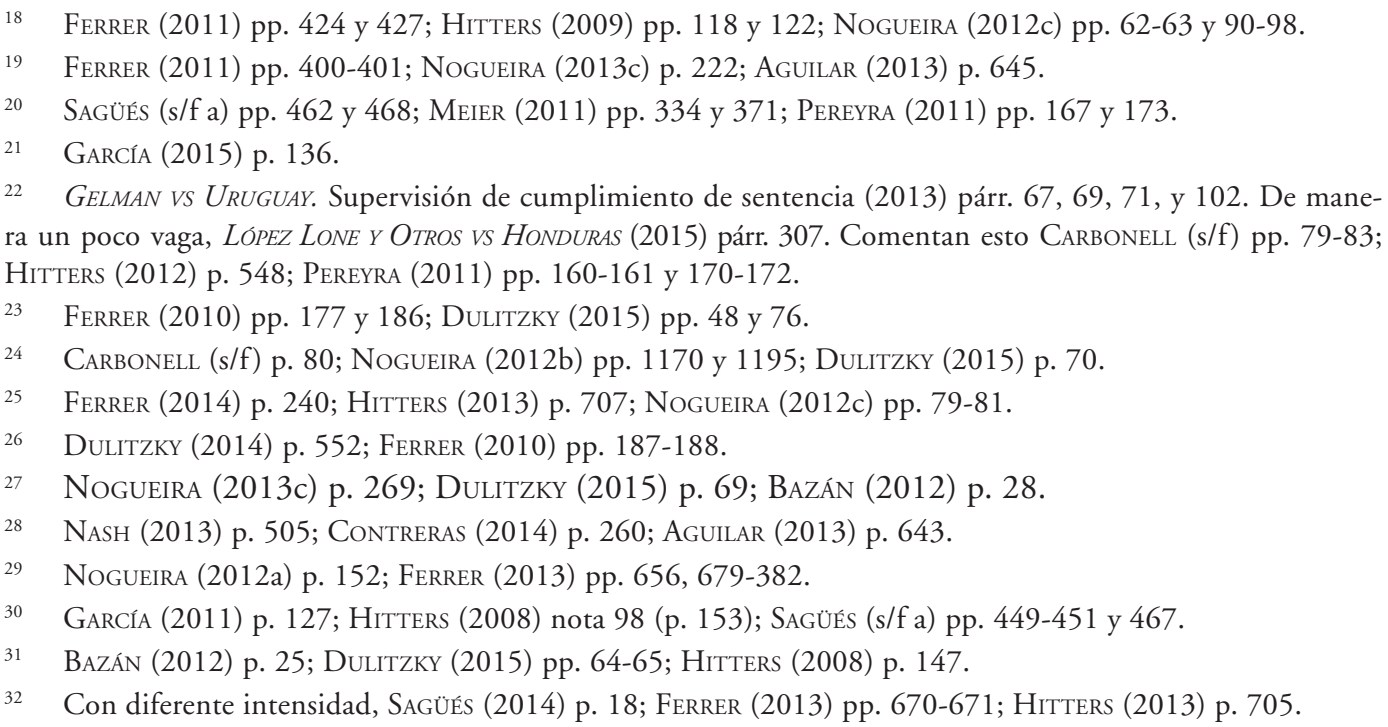


lidad: deben hacerlo de acuerdo con los criterios establecidos por la Corte, quien tendría siempre la última palabra en cuanto a su idoneidad ${ }^{33}$.

Ahora bien, siendo estos jueces locales los primeros guardianes de la Convención, su papel en la tutela de los derechos humanos debiera llegar más lejos. Es así como, por ejemplo, el profesor Nogueira ${ }^{34}$ los insta a aplicar "también los métodos de interpretación desarrollados por la CIDH: la interpretación evolutiva, dinámica y finalista; el uso de principios básicos de interpretación de derechos: 'pro homine' o 'favor persona', progresividad, proporcionalidad, para solo señalar algunos de ellos, los que constituyen una fuente de ampliación de su potestad jurisdiccional..." 35 .

Incluso, esta exigencia de interpretar el derecho local a la luz del internacional debiera ser aplicada de manera previa a cualquier otra forma de intentar desentrañar su sentido y alcance por parte del juez, quien debe hacer "relecturas adaptativas del derecho nacional, de tipo armonizante, en consonancia, esto es, 'conforme', con el Pacto y tal jurisprudencia. [...] En rigor de verdad, el juez local tendría que comenzar su análisis de la norma nacional a partir del Pacto de San José y de la aludida jurisprudencia, antes que iniciar el entendimiento de ella con los insumos jurídicos nacionales"36.

Sin embargo, debe advertirse que todo esto "implica pensar, interpretar y hacer funcionar a todo el derecho interno, de conformidad con las pautas del Pacto de San José de Costa Rica, y la jurisprudencia de la Corte Interamericana de Derechos Humanos" ${ }^{37}$.

Lo anterior, salvo, según se ha dicho, que usando el principio pro homine, se utilice la normativa interna, al considerarse más protectora e idónea que la internacional.

Es por eso que se ha señalado reiteradamente que el Derecho Internacional de los Derechos Humanos solo establece el "estándar mínimo"38 en la protección de estos derechos. De ahí que nada impida que los países establezcan una normativa más protectora a su respecto, o que los restrinjan en menor medida en los casos en que sea legítimo hacerlo. En consecuencia, en virtud del principio pro homine, el juez local estaría obligado a buscar la reglamentación más beneficiosa, sea esta nacional o internacional ${ }^{39}$.

Incluso se ha sostenido que el principio pro homine estaría dejando obsoletas las reglas de jerarquía dentro de los ordenamientos jurídicos. Es decir, el criterio jerárquico cedería ante el de mayor protección, pudiendo encontrarse dicha mejor tutela tanto en la normativa interna como la foránea ${ }^{40}$. Sin embargo, esta determinación dependerá, al me-

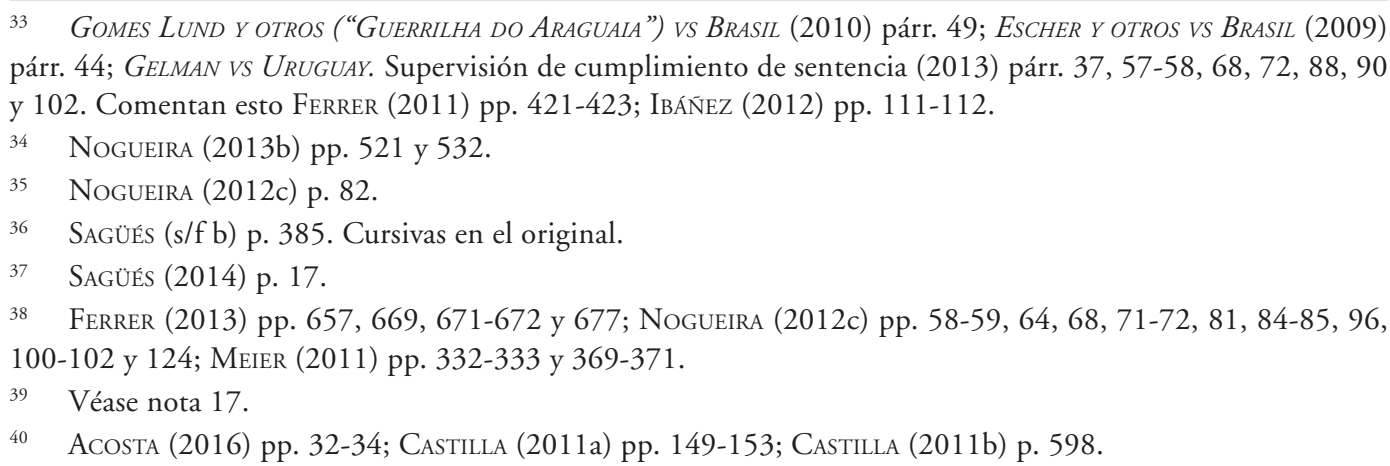


nos en un primer instante para estos 'jueces interamericanos', de las circunstancias de cada caso, siendo imposible determinarla a priori, aunque sea parcialmente ${ }^{41}$.

Con todo -muy importante para este estudio-, debe advertirse que la última palabra la tendría siempre la Corte Interamericana, pues según se ha dicho, en caso de llegar la causa a su conocimiento luego de agotadas las vías internas, no basta con que el Estado demandado señale que el juez local ejerció el control de convencionalidad, pues en teoría, el tribunal internacional siempre podría corregir su aplicación. Dicho de otra manera, más que hacer el control de convencionalidad, la Corte exige que se haga un uso correcto del mismo ${ }^{42}$.

De este modo, se formaría entre los jueces nacionales e internacionales un "diálogo interjurisdiccional", lo que generaría un enriquecimiento mutuo y en definitiva, una mejor protección de los derechos humanos en el sistema interamericano ${ }^{43}$.

En este mismo sentido, dado que el principio pro homine obliga al juzgador a buscar la normativa más favorable, también el profesor Nogueira ha señalado que en virtud de lo anterior, los jueces locales podrían mejorar los estándares alcanzados por la Corte no solo aplicando la normativa local en caso de ser más favorable, según se ha dicho, sino también extendiendo la interpretación de los instrumentos internacionales ya realizada por dicho tribunal, yendo así más lejos o incluso, abriendo nuevos y originales derroteros en materias respecto de las cuales no se haya pronunciado aún. Con todo, e igual que en los casos anteriores, el tribunal interamericano tendría siempre la última palabra, de llegar el caso a su conocimiento, pues en el fondo, y por mucha libertad e innovación que se busque conseguir con el principio pro homine, en teoría nada puede ir contra lo que este tribunal internacional considere correcto ${ }^{44}$, pues la idea es arribar a un ius commune o a un orden público interamericano.

De esta manera, entre otras posibilidades que plantea este autor, podrían existir:

a) Una interpretación extensiva, en la que, mediante su propia exégesis, el juez nacional podría ir más allá de lo establecido por la Corte en la protección de un derecho en particular. Estas decisiones nacionales podrían eventualmente influir en la Corte, aunque habrá que esperar su veredicto, mediante el cual ella tendría la libertad de aprobar o desaprobar dicha interpretación, siendo por ello un diálogo potencial ${ }^{45}$; o

b) Una interpretación innovadora, que es aquella en que se abordan derechos no analizados antes por la Corte, cuando existe silencio de su parte. Se crearía así una solución jurisprudencial inédita, en la cual el juez local "puede liberarse de la servidumbre de la ley nacional" ${ }^{46}$, teniendo la facultad de otorgar mayores alcances, aminorar restricciones, dar nuevos enfoques a los derechos involucrados y también de censurar a la norma nacional. Esto genera un "diálogo ascendente, el cual queda suspendido hasta que la CIDH conociendo de un caso análogo confirme o revierta la decisión adoptada por

\footnotetext{
41 SiLVA (2016) pp. 119-121 y 129-130.

42 Ferrer (2011) pp. 421-423; IbÁNez (2012) pp. 103 y 111-112.

43 Nogueira (2012a) pp. 149-187; Nogueira (2013a) pp. 221-274; Ferrer (2014) p. 240.

44 Nogueira (2012a) pp. 149-187; Nogueira (2013a) pp. 221-274; Nogueira (2013b) pp. 511-553.

45 Nogueira (2012c) pp. 89-90; Nogueira (2013b) pp. 531-532; Nogueira (2013c) pp. 234 y 248-249.

46 Nogueira (2012c) p. 90.
} 
el juez nacional” ${ }^{47}$. De esta manera, "El juez nacional debe proceder a esta innovación, estudiando la jurisprudencia interamericana para pronosticar cuál será la solución desarrollada por el juez interamericano en contenciosos inéditos. Si el juez nacional actúa de otra manera arriesga la condenación posterior de parte de la CIDH”48.

Por tanto, si se relaciona todo lo dicho hasta ahora respecto de la aplicación del control de convencionalidad y del principio pro homine, en teoría el juez interno podría:

a) Inaplicar la norma nacional en pos de la internacional (sea lo que fuere que esto signifique, lo que no puede ser analizado aquí);

b) Realizar una interpretación armonizante de la norma local con la internacional, lo que, por cierto, podría alterar notablemente su sentido y alcance;

c) Hacer primar la norma local, si a su juicio es más favorable;

d) Realizar una interpretación extensiva de la norma internacional, lo que podría a su vez, dar origen a la posibilidad $a$ ) o $b)^{49}$; y finalmente,

e) Hacer una interpretación innovadora de la norma internacional, con las dos mismas posibilidades señaladas en la letra anterior.

Se insiste en que la Corte debiera tener siempre la última palabra ante estas situaciones, para evitar que a través de su uso se 'traicionen' sus designios, al considerarse la intérprete oficial de la Convención ${ }^{50}$. Esto quiere decir que, si las autoridades locales no aplican el control de convencionalidad o lo hacen defectuosamente, se produciría una responsabilidad internacional para el Estado y podría ser demandado ante ella ${ }^{51}$. O si se prefiere, no basta con que el juez local alegue haber ejercido el control interno, ya que la Corte no queda inhabilitada para aplicar su propio -y externo- control de convencionalidad ${ }^{52}$.

Hasta aquí los principales postulados de la teoría del control de convencionalidad defendidos por la doctrina mayoritaria, que nos servirán como punto de referencia para cotejar dicho planteamiento con el real nivel de eficacia que han tenido las sentencias en que la Corte ordena llevarlo a cabo. A continuación, se señalarán algunos aspectos metodológicos que han sido utilizados para la realización del presente trabajo y la determinación del grado de cumplimiento de las sentencias en que la Corte ordena aplicar este control, y que explican la estructura de los anexos I y II del mismo.

\section{ALGUNOS ELEMENTOS METODOLÓGICOS A TENER EN CUENTA}

Tal como se ha dicho, en el presente estudio se analiza la eficacia de los fallos en que la Corte Interamericana ha ordenado realizar el control de convencionalidad. El fundamento para circunscribir dicho análisis solamente a estas resoluciones obedece a tres razones.

\footnotetext{
47 Nogueira (2012c) p. 90.

48 Nogueira (2013c) p. 234. Para estas ideas, Nogueira (2012c) pp. 89-91, 103 y 110-121; Nogueira (2013b) pp. 521-522 y 532-533.

49 Ello, pues parece poco probable que el juez local realice una interpretación extensiva o innovadora si quisiera aplicar la normativa nacional en virtud del principio pro homine visto en la letra anterior.

50 Nogueira (2012c) pp. 90-98; Aguilar (2012) pp. 727-728 y 740-742; Hitters (2009) pp. 118 y 122.

51 BazÁn (2010) pp. 170-173; CANÇADo (2006) pp. 416-417; TAPIA (2008) pp. 133-134.

52 Ferrer (2010) p. 22; Sagüés (s/f b) pp. 385-386; Contesse (2013) p. 15.
} 
La primera es por motivos de espacio: el solo anexo con la totalidad de los fallos de la Corte y su estado actual ocuparía más páginas que este trabajo.

La segunda se debe a la importancia teórica que poseen estas resoluciones: al ser una creación pretoriana ${ }^{53}$, la eventual fuerza normativa del control de convencionalidad proviene únicamente de los fallos que lo consagran (y de las opiniones consultivas que lo establecen ${ }^{54}$, tema que no se analiza aquí). Además, la Corte ha ido ampliando sus alcances por esta misma vía. Por eso resulta absolutamente necesario analizar cuál ha sido el nivel de cumplimiento de estos fallos.

Finalmente y en tercer lugar, debido a que si la Corte pretende que el control de convencionalidad tenga efectos erga omnes, parece lógico que este sea aplicado primero por los Estados condenados por las sentencias que lo establecen (en virtud de su efecto inter partes, de acuerdo al art. 68.1 de la Convención), pues a nuestro juicio, esta obligación resulta más perentoria -y por tanto su incumplimiento más grave- en estos casos, los únicos en los que además, la Corte puede seguir su evolución mediante supervisiones de cumplimiento.

Todo esto explica, pues, nuestro especial interés en estos fallos en particular.

Por último, debe hacerse presente que, para indagar en el grado de cumplimiento de los mismos, no se han analizado los motivos que para ello puedan haber existido en cada país -lo cual excedería los límites del presente estudio-, sino solamente los datos suministrados por la misma Corte en su página web ${ }^{55}$. Lo importante para estos efectos, es que independientemente a su causa, se cuenta con un dato objetivo: el real nivel de cumplimiento de los fallos que consagran el control de convencionalidad, aspecto que, a nuestro juicio, debe ser tomado muy en cuenta al momento de abordar la teoría del mismo.

Para determinar este nivel de cumplimiento, primero se hizo un catastro general de las sentencias de los casos contenciosos dictados por este tribunal. De acuerdo con la información de su sitio web, hasta el 31 de diciembre de $2017^{56}$, la Corte ha emitido un total de 344 sentencias. Sin embargo, lo anterior no significa que se hayan decidido el mismo número de casos, en atención a que existen varios que poseen más de un fallo. Lo anterior ocurre, porque además de las sentencias de fondo, existen sentencias de excepciones preliminares, de reparaciones y costas, de cumplimiento de sentencias y de interpretación de todas ellas. De ahí que los casos reales sean en verdad, 227.

De estas 227 sentencias de fondo, la Corte alude al control de convencionalidad en 42 de ellas ${ }^{57}$, si bien las remisiones de unas a otras y las repeticiones son muy abundantes. También dentro de estos mismos casos, se menciona esta materia en 3 resoluciones de in-

53 Olano (2017) pp. 66 y 87; Aguilar (2016b) p. 131; Ferrer (2016) pp. 340 y 342.

54 SAGǗs (2015) pp. 275-283.

55 http://www.corteidh.or.cr/index.php/es

56 La última visita a todos los sitios web que se indican en este trabajo fue realizada el 29 de marzo de 2018.

57 El control de convencionalidad también es mencionado en otras sentencias que no se consideran en este trabajo, en razón a que no es propiamente la Corte la que lo hace, sino la Comisión Interamericana (MOHAMED vs Argentina, de 2012, Omar Humberto Maldonado Vargas y otros vs Chile, de 2015 y Duque vs Colombia, de 2016) el Estado (como en las interpretaciones de sentencias de fondo de OSORIO RIVERA Y FAMILIARES VS PERÚ, de 2014) los representantes de las víctimas (NADEGE DORZEMA Y OTROS VS REPÚBLICA DOMINICANA, de 2012 y DUQUE VS Colombia, de 2016). Tampoco se han considerado los comentarios sobre esta cuestión vertidos en votos razonados, concurrentes o disidentes. 
terpretación de sentencia de fondo ${ }^{58}$ y en 14 supervisiones de cumplimiento (en adelante, S.C. $)^{59}$. Toda esta información consta en el anexo I del presente trabajo.

Ahora bien, puesto que las alusiones al control de convencionalidad no aparecen solo en las sentencias de fondo, lo anterior nos llevó a investigar si la Corte aludía al mismo en otras causas. Fue así como descubrimos que además de los 42 casos recién señalados, lo hace en 26 causas más, no en sus sentencias de fondo, sino en 38 S.C., y en una medida provisional (en adelante, M.P.). Esta información aparece en el anexo II de este estudio.

De esta manera, hasta finales de 2017 , en realidad la Corte ha abordado expresamente el tema del control de convencionalidad en 68 causas, desglosándose en 42 sentencias de fondo, 3 sentencias de interpretación, 52 S.C. y 1 M.P. En cada caso, se indica el o los párrafos en que se alude al control de convencionalidad. Finalmente, debe dejarse constancia que, respecto de las S.C., ellas se han contabilizado no de acuerdo con el número de resoluciones de esta clase que se han dictado, sino a la cantidad de causas a las que aluden, pues es frecuente que se refieran a más de un caso, si bien siempre referidos al mismo país.

En ambos anexos también se indica el estado actual de cada caso, siempre de acuerdo con la información suministrada por la página web de la Corte (en el link "Casos en Etapa de Supervisión" ${ }^{60}$ ) y las S.C. de cada uno de ellos, en el evento de haberlas, haciéndose la remisión a sus párrafos fundamentales a pie de página para cada causa.

De esta manera, el estado actual de las causas puede arrojar 4 resultados: Cumplimiento Total, Cumplimiento Parcial, Incumplida y Pendiente.

Ahora bien, para distinguir entre estas cuatro posibilidades, se procedió a separar, de acuerdo a su naturaleza, entre las diferentes obligaciones que la Corte exige a los Estados. En consecuencia, dichas obligaciones se pueden agrupar del modo que sigue: a) Pago de indemnizaciones en general; $b$ ) Pago de costas y otros gastos; c) Obligación de investigar y eventualmente sancionar a los responsables de las violaciones constatadas, lo que incluye la búsqueda de posibles restos de las víctimas en caso de haberlos; d) Realización de las modificaciones legales ordenadas por el fallo; e) Realización de diversas medidas de desagravio (acto público de reconocimiento de responsabilidad internacional, publicación de extractos del fallo en un periódico local, construcción de monumentos, cambio de nombres de lugares públicos, etc.) y f) Otras medidas (atención médica y/o psicológica, becas, etc.).

Evidentemente, el cumplimiento de estas obligaciones posee un muy dispar nivel de dificultad. Así, por ejemplo, es mucho más complejo efectuar modificaciones legales que publicar un extracto de una sentencia. Ello explica que no se haya procedido a su simple cuantificación global sin distinguirlas entre sí, pues ello podría inducir a confusión. De ahí que las obligaciones $a$ ), c) y $d$ ) hayan sido consideradas las fundamentales y es en torno a

58 En FERnández ORTEGa y otros vs México y Rosendo CANTÚ y otra VS MÉxico, ambos de 2010.

59 En Radilla Pacheco vs México (2009) en sus S.C. de 2012, 2013 y 2015; FernándeZ ORTEGA Y otros VS MÉxico (2010) en su S.C. de 2015; Rosendo CANTÚ Y OtRa VS MÉXICO (2010) en su S.C. de 2015; Gomes LUND

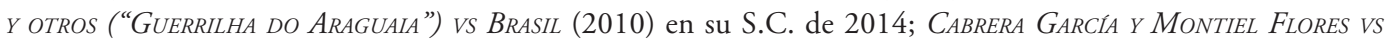
MÉXICO (2010) en sus S.C. de 2013 y 2015; GELMAN VS URUGUAY (2011) en su S.C. de 2013; MASACRES DE RIO Negro vs Guatemala (2012) en su S.C. de 2014; y Gudiel Álvarez y otros (Diario Militar) vs Guatemala (2012) en su S.C. de 2014.

60 http://www.corteidh.or.cr/cf/jurisprudencia2/casos_en_etapa_de_supervision.cfm. 
su grado de cumplimiento que se realiza la clasificación señalada, a pesar de que al compararlas entre sí, igualmente resulte bastante más fácil pagar una indemnización que realizar modificaciones legales o investigar los hechos.

De esta forma, las causas con Cumplimiento Total (en adelante C. Total) son aquellas en que la Corte ha señalado mediante una S.C., que el Estado ha dado satisfacción a todas las obligaciones impuestas en el fallo de fondo, ordenando así archivar la causa y además, aparecen en la sección "Casos en etapa de Supervisión archivados por cumplimiento" ${ }^{61}$.

Las causas con Cumplimiento Parcial (C. Parcial) son aquellas en que el Estado ha satisfecho solo a medias sus obligaciones, por ejemplo, si ha pagado las indemnizaciones o su mayor parte, aun cuando no se hayan iniciado o solo parcialmente las investigaciones correspondientes y/o no se hayan introducido las modificaciones legales señaladas por la Corte, pese a que como se ha dicho, resulte bastante más fácil lo primero que estas dos últimas medidas. Es decir, el solo pago de las indemnizaciones o al menos en su mayor parte, ha sido considerado aquí como un C. Parcial, razón por la cual, en el presente estudio, el nivel de exigencia para estimar que una causa cae dentro de esta clasificación ha sido bastante bajo. En caso contrario, varias causas más habrían sido clasificadas dentro del grupo que sigue.

Las sentencias Incumplidas son aquellas en que lo anterior no ha ocurrido, o el nivel de cumplimiento es mínimo (por ejemplo, solo se ha publicado el fallo en un periódico local o se ha realizado un acto público de desagravio, pero no se ha indemnizado a las víctimas ni procesado a los presuntos culpables, o hecho modificaciones legales).

Finalmente, las causas Pendientes son aquellos litigios demasiado nuevos, que, además, no poseen ni S.C. ni M.P. posteriores al fallo de fondo, aunque estas últimas sí pueden haberse dictado antes del mismo. Igualmente, se ha tomado en cuenta la información oficial del link "Casos en Etapa de Supervisión" ya aludido. Como no poseen S.C., tampoco existe información a su respecto a pie de página. Con todo, lo importante es recalcar que se encuentran Incumplidas o con C. Parcial -pues si tuvieran un C. Total, la Corte ya habría dejado constancia de ello-, aunque no sea posible determinar en cuál ambos estados, de acuerdo con la información indagada para este estudio. Con todo, que se encuentren en una u otra situación no ha influido mucho en los resultados del presente estudio.

Conviene tener en cuenta que, respecto de estas causas Pendientes, existen otros datos que dan pistas sobre su estado de avance, como por ejemplo, videos de audiencias ${ }^{62} \mathrm{o}$ "comunicados prensa" ${ }^{3}$. Sin embargo, no hemos tomado en cuenta la información que allí aparece, hasta que no conste de manera oficial en alguna resolución de la propia Corte.

Corresponde ahora hacer algunas reflexiones sobre el nivel de cumplimiento que han tenido los casos en que la Corte Interamericana ha ordenado aplicar el control de convencionalidad, información que consta en los anexos I y II de este trabajo.

\footnotetext{
${ }_{61}$ http://www.corteidh.or.cr/cf/jurisprudencia2/casos_en_etapa_de_supervision_archivados_cumplimiento. cfm?lang=es.

62 http://www.corteidh.or.cr/index.php/al-dia/galeria-multimedia.

63 http://www.corteidh.or.cr/index.php/es/al-dia/comunicados.
} 


\section{ALGUNAS REFLEXIONES A PARTIR DE LOS DATOS OBTENIDOS}

El aspecto fundamental que salta a la vista a partir de la información suministrada en los anexos I y II, es el notable nivel de ineficacia que presentan los casos en que la Corte Interamericana ha ordenado aplicar el control de convencionalidad, lo cual muestra una gran resistencia de los Estados a seguir sus dictámenes. Ello, pues debe tomarse muy en cuenta que, en este estudio, el criterio para determinar si una causa posee C. Parcial es bastante bajo, al ser mucho más fácil pagar una indemnización o incluso parte de ella que hacer las modificaciones legales o las investigaciones judiciales ordenadas por la Corte.

Además, este bajo nivel de cumplimiento genera un no menor desgaste procesal para este tribunal, al verse obligado a emitir numerosas resoluciones anexas (solicitudes de interpretación de las sentencias de fondo, M.P., y S.C., entre otras, la gran mayoría de las cuales no se mencionan en este trabajo), a fin de obtener dicho cumplimiento, con resultados desalentadores en no pocas ocasiones.

Ello explica que en las causas en que se establece el control de convencionalidad en la sentencia de fondo (anexo I), solo existan dos con C. Total (FAMILIA PACHECO TINEO VS BOLIVIA, de 2013 y GARCÍA IBARRA Y OTROS VS ECUADOR, de 2015) y en aquellas en que se lo menciona en una S.C. (anexo II), haya solamente tres en esta condición (CASTILLO PETRUZZI y otros vs Perú, de 1999, Lori Berenson Mejía vs Perú, de 2004 y Castañeda Gutman vs MÉXICO, de 2008).

Otro aspecto que llama profundamente la atención es que dentro de estas causas existen algunas, consideradas emblemáticas y que son mencionadas prácticamente en todos los trabajos en que la doctrina habla del control de convencionalidad, que se encuentran Incumplidas. Esto es particularmente notorio en los Casos TRABAJADORES CESADOS DEL CONgreso (Aguado Alfaro y otros) vs Perú y La Cantuta vs Perú, ambos de 2006. Y las otras causas tanto o más emblemáticas que las anteriores, se encuentran con C. Parcial: ALMOnacid Arellano y otros vs Chile, de 2006, Radilla Pacheco vs MéXico, de 2009, Cabrera García y Montiel Flores vs México, de 2010 y Gelman vs URUGUAY, de 2011.

De manera más general, respecto de aquellas otras causas en que el control de convencionalidad no es mencionado en las sentencias de fondo, sino casi siempre en una S.C., llama la atención el estado de Incumplimiento y hasta de abandono de varias de ellas. En primer lugar, las que afectan a Guatemala, como expresa la Corte en la S.C. 12 CASOS GUATEMALTECOS vS GUATEMALA, de $2015^{64}$. Fuera de las causas referidas a Guatemala, también deben tenerse en cuenta sobre todo los casos LOAYZa TAMAYO vs PERÚ, de 1997, BarRIOS Altos vs Perú, de 2001, “Cinco Pensionistas" vs Perú, de 2003 y Masacres de Ituango vs Colombia, de 2006.

Por último, debe señalarse la situación particularmente grave de desacato de los casos Apitz Barbera y otros ("Corte Primera de lo Contencioso Administrativo") vs Venezuela, de 2008 y LÓPEZ MENDOZA VS VENEZUELA, de 2011, los que han sido notificados a la Asamblea General de la OEA, de acuerdo con lo establecido por el art. 65 de la Convención

64 S.C. 12 Casos guatemaltecos vs Guatemala (2015) en particular, párr. 20, 126, 170, 174 y 175. 
Americana de Derechos Humanos. Igualmente, también ha generado una notable polémica en el último tiempo la situación del caso FONTEVECCHIA Y D'AMICO VS ARGENTINA ${ }^{65}$.

De esta forma y resumiendo, en los casos en que la Corte ordena realizar el control de convencionalidad en su sentencia de fondo, el nivel de cumplimiento de estos puede ser representado de la manera siguiente ${ }^{66}$ :

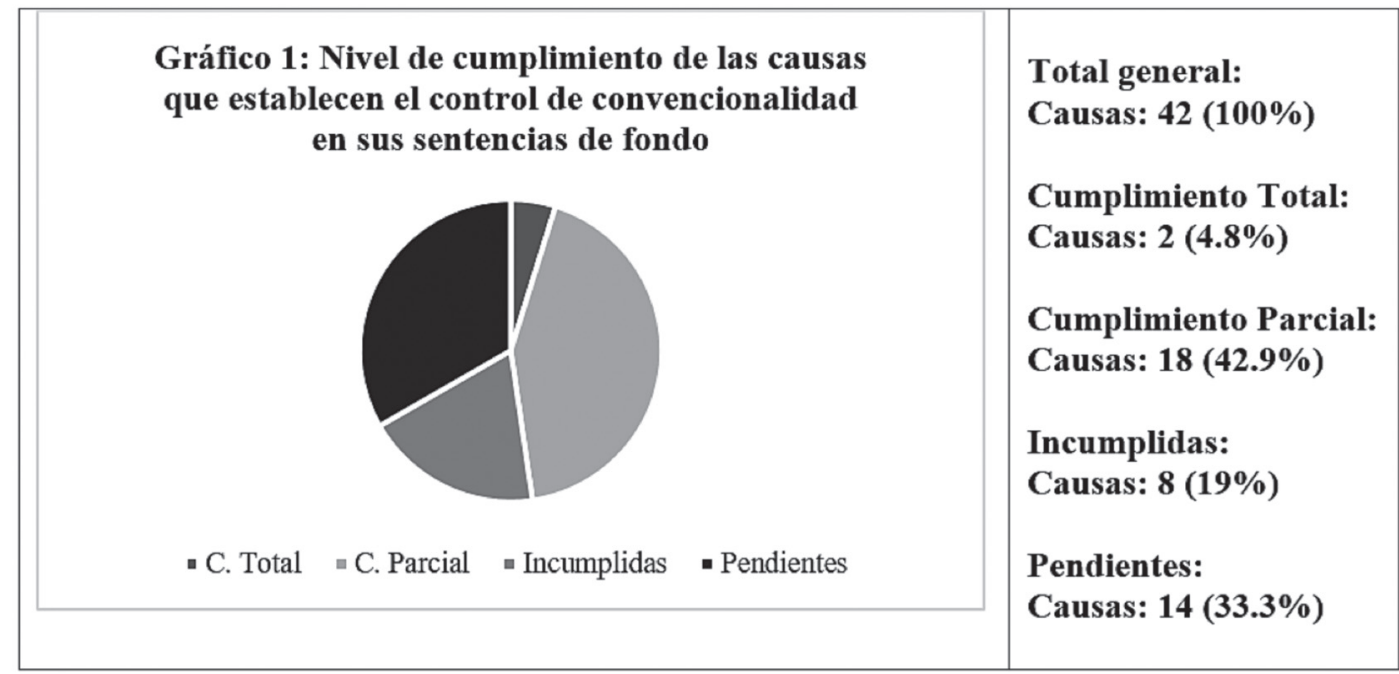

Por otro lado, si se toman en cuenta todas las causas en que la Corte alude al control de convencionalidad analizadas en el presente trabajo, la situación es esta ${ }^{67}$ :

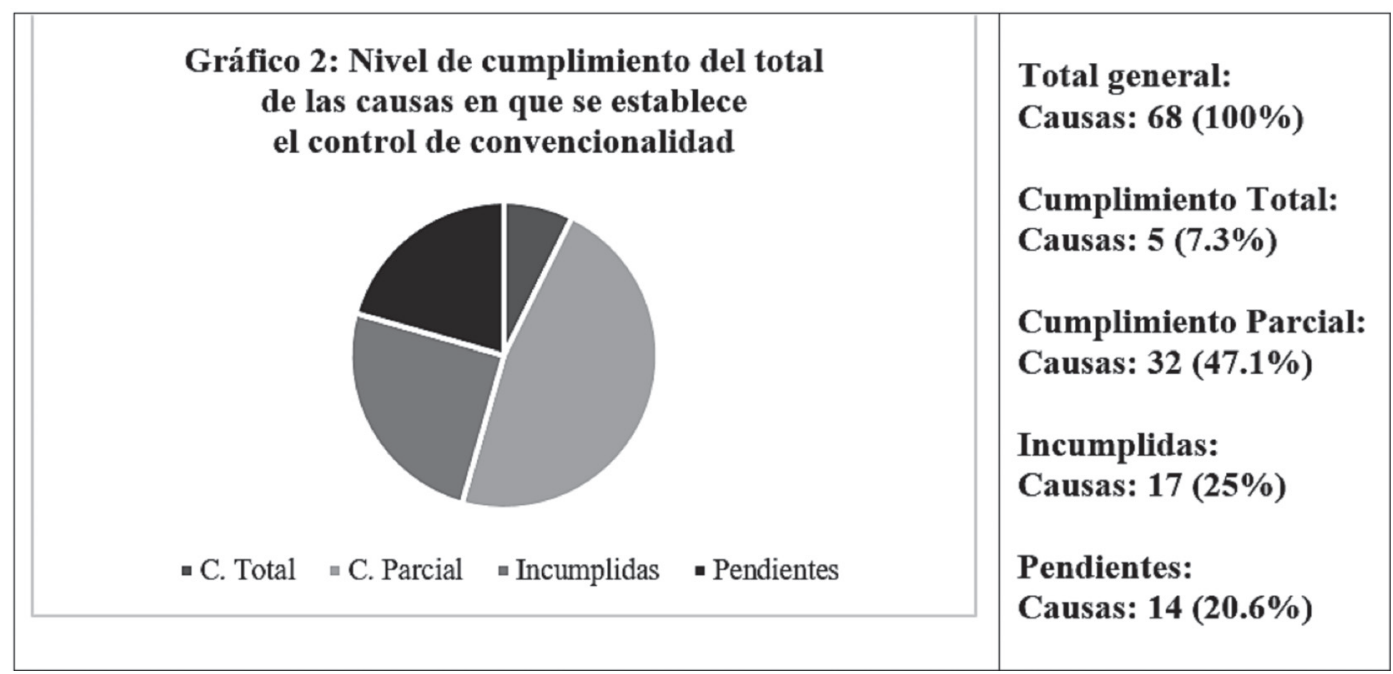

65 Abramovich (2017) pp. 9-25; Furfaro (2017) pp. 37-79.

66 Fuente: elaboración propia.

67 Fuente: elaboración propia. 
Por tanto, puede concluirse que el nivel de cumplimiento de las causas en que la Corte establece y aboga por el control de convencionalidad es muy bajo, lo que en parte podría deberse, además de la resistencia de los Estados, a las múltiples prestaciones que se establecen en las sentencias de fondo, lo que sin duda dificulta su cumplimiento ${ }^{68}$.

\section{UN MODO DIFERENTE DE PLANTEAR LA DOCTRINA DEL CONTROL DE CONVENCIONALIDAD}

Ahora bien, si se toma en cuenta la baja eficacia de los fallos que ordenan realizar el control de convencionalidad ya comentada, resulta lícito preguntarse si la consideración de este dato poco conocido y casi siempre omitido podría influir en el modo de abordarlo, o si se prefiere, si la manera en que la doctrina mayoritaria lo ha planteado sería distinta, si se añadiera esta información.

A nuestro juicio la respuesta es positiva, en particular y fundamentalmente, debido al papel protagónico que se le asigna la Corte para que dicho control sea ejercido correctamente. Por eso puede decirse sin temor a equivocarse, que la Corte Interamericana es la piedra angular del mismo. Esta es la razón por la cual estimamos que este nuevo dato es un factor clave que debe añadirse necesariamente al modo de plantear la doctrina del control de convencionalidad, todo lo cual altera notablemente su resultado final, al punto de hacerlo bastante inviable, al menos del modo en que actualmente se lo expone.

Para demostrar lo anterior, se procederá a replantear los principales puntos de la teoría del control de convencionalidad expuesta en el epígrafe 1, tomando en cuenta esta nueva información. Para ello, se analizará hipotéticamente primero la situación que se produce respecto del país condenado en la sentencia que lo establece (en virtud de su efecto inter partes), tanto respecto del control externo que realiza la propia Corte, como del interno que luego debieran llevar a cabo las autoridades locales. Más tarde y en este mismo orden -externo e interno-, se analizará el llamado efecto erga omnes del control de convencionalidad.

Respecto del efecto inter partes, y aun cuando sea un dato previsible, el escaso nivel de efectividad de los fallos que se analizan en este estudio prueba fehacientemente que por mucho que este tribunal realice un control de convencionalidad externo, casi no tiene cómo forzar a los Estados condenados a acatar sus sentencias, pues dicho acatamiento siempre dependerá de medidas internas adoptadas por ellos mismos, por mucho que presione este tribunal internacional entre otras vías, mediante sus S.C.

Por eso es necesario aclarar (pues da la impresión que a veces la doctrina lo pasara por alto) que no es lo mismo ordenar hacer algo, como ocurre en el control de convencionalidad, que llevarlo a cabo por sí mismo (en este caso, por la propia Corte), ya que toda obligación es de suyo violable, como por lo demás, muestra el presente estudio.

Sin embargo, por regla muy general, este escaso nivel de cumplimiento es un dato omitido por los autores que analizan y abogan por el control de convencionalidad. A lo sumo señalan algunos que en caso de no estar de acuerdo con lo fallado, al Estado no le

68 Si bien no referido a este problema de ineficacia, abordan estas múltiples prestaciones desde ópticas distintas, Paúl (2013) pp. 314-317 y 337-340; Malarino (2011) pp. 27-29, 49-53 y 59-61. 
quedaría más alternativa que denunciar el tratado, casi como si fuera una disyuntiva insalvable $^{69}$. Mas lo cierto es que en los hechos, los países que han dado competencia a la Corte siguen reconociéndosela -salvo Venezuela-, aun cuando el nivel de acatamiento de sus fallos resulte bajo ${ }^{70}$.

Ahora, si existen estas serias limitaciones respecto del control externo en relación con el Estado condenado, con mayor razón hay escasas posibilidades de fiscalizar, primero que se realice el control de convencionalidad interno dentro de ese país y supuesto lo anterior, que se haga de manera correcta. Sin embargo, la doctrina mayoritaria señala insistentemente que cualquiera sea el camino que adopte el juez nacional (a saber: inaplicar la norma nacional, realizar una interpretación conforme, hacer prevalecer la norma local, y también para algunos, dar origen a una interpretación extensiva o incluso a una interpretación innovadora), debe hacerlo siguiendo los criterios de la Corte, y que en caso contrario, estaría dando origen a responsabilidad internacional del Estado, pues este tribunal debiera tener siempre la última palabra a fin que se haga un adecuado control de convencionalidad. Con todo, a menos que la causa específica en la cual no se haya aplicado o se haya aplicado incorrectamente dicho control llegue a su conocimiento luego de agotadas las instancias internas, en los demás casos resulta imposible su fiscalización por esta Corte. Desde este postulado pues, el papel protagónico que se le asigna a la Corte parece bastante inviable.

En realidad, la única fiscalización posible podría lograrse en el evento de existir un convencimiento por parte de los jueces locales de seguir los criterios de la Corte, en particular de los tribunales superiores de cada país, lo que en parte podría lograrse gracias al 'diálogo interjurisdiccional' por el que tanto se aboga. Mas este acatamiento no solo depende exclusivamente de las autoridades locales, sino, además, nada asegura que sigan fielmente los criterios de este tribunal internacional, como sería por ejemplo, si se inspiraran solo en el tratado y no en sus fallos, o en jurisprudencia más antigua emanada del mismo.

Una imposibilidad semejante de fiscalización existe, si bien no ha sido abordada en este trabajo, respecto del control interno de convencionalidad que, según la Corte, debieran realizar los demás poderes del Estado e incluso las instancias democráticas: salvo que un caso particular de inconvencionalidad llegue a su conocimiento luego de agotadas las vías internas, no hay manera que este tribunal pueda tomar cartas en el asunto. Mal puede ser así el control de convencionalidad un 'rayo exterminador de normas locales', como se ha señalado, ni tampoco permite necesariamente arribar a un ius commune interamericano.

Sin embargo, aún en los casos en que la actuación inconvencional interna llegue efectivamente al conocimiento de la Corte, volvemos al problema inicial de cualquier control de convencionalidad externo: la imposibilidad para este tribunal de forzar su ejecución por parte del Estado condenado.

Dicho de otra manera: para la Corte, la única forma de fiscalizar una adecuada realización del control de convencionalidad interno es a través del ejercicio del control externo, para lo cual es necesario que el caso llegue a su conocimiento y de ser así, que el Estado lo acate.

69 SAGÜÉS (2010) p. 125; SAGÜÉS (s/f a) pp. 456-458; Salgado (2012) p. 236.

70 Desde ópticas muy diferentes, HaWkins y Jacoby (2010) pp. 39, 43 y 51; CanÇAdo (2013) pp. 32-34. 
Por eso, por mucho que se diga que el país caería en responsabilidad internacional por no aplicar el control de convencionalidad (externo o interno) o aplicarlo incorrectamente, dicha responsabilidad puede muy bien quedar solamente en el papel, pues a lo sumo generaría una nueva responsabilidad internacional ${ }^{71} \mathrm{y}$ así sucesivamente.

Finalmente, si existen problemas para fiscalizar la aplicación del control de convencionalidad externo e interno respecto del país condenado por un fallo de la Corte en virtud de su efecto inter partes, con mucha mayor razón estos problemas se agudizan sobremanera respecto del resto de los países que en teoría, también debieran aplicarlo gracias al hipotético efecto erga omnes de este control. Ello, a menos que también aquí exista un convencimiento de los jueces nacionales para emplear los criterios de la Corte con preferencia a los suyos, pero que a diferencia de lo que ocurría en el caso anterior, con el añadido que estén dispuestos además a seguir los lineamientos establecidos por ella en causas en que su país no ha sido parte. Mas, salvo este caso, la única forma de controlar que se haga o se haga correctamente el control de convencionalidad en estos otros países, sería que esa situación llegue al conocimiento de la Corte, produciéndose los mismos problemas ya señalados a propósito del efecto inter partes.

Por tanto, al menos tal como están las cosas al día de hoy, no parece posible poder fiscalizar el actuar de estos juzgadores nacionales a los que la Corte pretende convertir en 'jueces interamericanos', de tal forma que a la postre, lleguen a conocimiento de este tribunal internacional solo los casos en que no se haya aplicado o se haya empleado incorrectamente el control de convencionalidad. Por lo mismo, no parece tan fácil que pueda generarse un efecto multiplicador de sus fallos y llegar así a un ius commune interamericano. Salvo que exista un acuerdo en tal sentido por parte de los jueces locales de cada país según se ha dicho, y que además, coincida con los criterios de la Corte Interamericana, no se ve forma en que puedan producirse estos efectos.

Dicho de otra manera y englobando todo lo señalado en este epígrafe, se puede decir que existe una falta de control sobre el control de convencionalidad. Ello, porque en la práctica, la Corte no tiene manera de tomar medidas efectivas para garantizar primero que se aplique su propio control de convencionalidad externo, ni mucho menos, para que los jueces locales lo realicen y supuesto lo anterior, que lo hagan correctamente.

Todo lo dicho $-\mathrm{y}$ esto es fundamental-, sin perjuicio que si la Corte falla aproximadamente unos 25 casos por año, resulta absolutamente imposible que pueda supervigilar a los miles y miles de fallos que se emiten en todo el continente ${ }^{72}$.

Por tanto, podría decirse que el bajo cumplimiento de las sentencias de la Corte proyecta una notable sombra de duda sobre la doctrina del control de convencionalidad, tanto en su planteamiento teórico como en su aplicación práctica.

Más aún: al ser imposible que la Corte tenga siempre la última palabra, se podría producir un efecto exactamente opuesto al deseado: una completa dispersión de enfoques en cuanto a la aplicación de la Convención y de la jurisprudencia de este tribunal. Por tanto, no resulta tan fácil que todo el derecho interno de cada país acabe siendo 'pensado,

$71 \quad$ ViO (2015) pp. 99-103.

72 Dulitzky (2014) pp. 552-553; Dulitzky (2015) pp. 48, 70-73 y 76; Silva (2016) pp. 125-128. 
interpretado y hecho funcionar' de acuerdo con la jurisprudencia de la Corte, como alguna vez se ha mencionado.

Finalmente, y de manera más global, creemos que la omisión del real nivel de cumplimiento de los fallos de la Corte puede hacer caer en el error de pensar que su acatamiento es relativamente alto. De hecho, debemos confesar la profunda sorpresa que nos causó descubrir este hecho, bastante poco conocido (pues en caso contrario, sería objeto de análisis) luego de haber investigado durante bastante tiempo la teoría del control de convencionalidad tal como la presenta la doctrina mayoritaria. Precisamente este hallazgo fue lo que motivó la realización del presente estudio.

Por eso, aun cuando se comprenda el interés de la doctrina por lograr la mayor eficacia posible de las sentencias de la Corte con el fin de conseguir una mejor protección de los derechos humanos en la región, nos parece que omitir este dato puede inducir a error, pues la apariencia teórica del control de convencionalidad -que incluso puede dar una sensación de invulnerabilidad, o hasta de tratarse de un hecho consumado- es muy distinta de su realidad práctica. De ahí que esta falta de control sobre el control de convencionalidad lo haga, a nuestro juicio, inviable, al menos tal como es planteado por la doctrina mayoritaria.

\section{CONCLUSIONES}

La principal conclusión del presente trabajo es que, si se tomara en cuenta el real nivel de cumplimiento que han tenido las causas en que la Corte Interamericana ha ordenado aplicar el control de convencionalidad, la teoría del mismo debiera ser reformulada a la luz de este dato poco conocido.

En realidad, este bajo nivel de cumplimiento demuestra un aspecto que se intuye pero que conviene tener claro: que la Corte no tiene manera de obligar a que los Estados acaten sus fallos. Por eso la teoría del control de convencionalidad, tanto externo como interno resulta inviable, al menos del modo en que actualmente lo plantea la doctrina mayoritaria, puesto que resulta imposible que este tribunal pueda tener el papel protagónico que le asigna para su correcto funcionamiento.

Lo anterior, sin perjuicio de su imposibilidad fáctica para supervigilar los fallos de todo un continente, en atención al bajo número de sentencias que dicta cada año.

Por eso, a nuestro juicio resulta contradictorio el modo en que sobre todo la doctrina plantea la teoría del control de convencionalidad -con un aplomo y una seguridad que casi dan la impresión de estar ante una situación consolidada-, con el real nivel de cumplimiento de los fallos paradigmáticos (y otros varios más) en que se apoya. Ello, sin perjuicio que al no estar establecido en la Convención Americana, estos fallos sean el único sustento del control de convencionalidad, dado su origen pretoriano.

En parte esta escasa eficacia puede deberse, según se ha indicado, a las abundantes obligaciones que establece la Corte en cada sentencia de fondo, lo que las hace difíciles de cumplir, además de requerir de un largo tiempo, todo lo cual genera igualmente, un notable desgaste para este tribunal, al obligarlo a dictar tantas resoluciones anexas. Pero creemos que eso no es suficiente para explicar la situación descrita. 
En consecuencia, lo anterior significa que la doctrina mayoritaria no presenta las cosas tal como son, sino del modo que, desde su perspectiva, debieran ser. Un planteamiento de estas características es perfectamente lícito, pero debiera advertir sobre lo que realmente ocurre en la práctica, pues en caso contrario, puede inducir a confusión. Por eso sería deseable que la dogmática también considerará el resultado práctico de sus postulados, incorporando esta variable en la construcción de sus conceptos teóricos.

Todo esto hace sospechar que la teoría del control de convencionalidad ha sido formulada de manera demasiado teórica y que no se han tomado debidamente en cuenta la realidad de su funcionamiento ni sus verdaderas posibilidades de implementación.

Lo anterior se explica entre otras cosas, pues por mucho que la Corte Interamericana busque erigirse en una especie de tribunal constitucional continental, sigue siendo un tribunal internacional y, por tanto, depende fundamentalmente de los Estados para la eficacia de sus decisiones, en virtud de su carácter subsidiario en la protección de los derechos humanos.

\section{BIBLIOGRAFÍA CITADA}

Abramovich, Víctor (2017): "Comentarios sobre 'Fontevecchia', la autoridad de las sentencias de la Corte Interamericana y los principios de derecho público argentino", Pensar en Derecho, Universidad de Buenos Aires, No 10, Año 5: pp. 9-25.

Acosta Alvarado, Paola Andrea (2016): "Zombis vs Frankenstein: sobre las relaciones entre el Derecho Internacional y el Derecho interno", Estudios Constitucionales, Año 14, No 1: pp. 15-60.

Aguilar Cavallo, Gonzalo (2016a): "Los derechos humanos como límites a la democracia a la luz de la jurisprudencia de la Corte Interamericana de Derechos Humanos", Revista da AJURIS, Porto Alegre, Vol. 43 No 141: pp. 337-365.

Aguilar Cavallo, Gonzalo (2016b): "Constitucionalismo global, control de convencionalidad y el derecho a huelga en Chile", Anuario Colombiano de Derecho Internacional (ACDI), Vol. 9: pp. 113-166.

Aguilar Cavallo, Gonzalo (2013): “Afinando las cuerdas' de la especial articulación entre el Derecho Internacional de los Derechos Humanos y el Derecho Interno", Estudios Constitucionales, Año 11, No 1: pp. 633-654.

Aguilar Cavallo, Gonzalo (2012): "El Control de Convencionalidad de los derechos. Comentario a la sentencia de la Corte Suprema de Chile en el caso denominado Episodio Rudy Cárcamo Ruiz de 24.5.12”, Estudios Constitucionales, Año 10, o 2: pp. 717-750.

BAZÁN, Víctor (2012): "El control de convencionalidad: incógnitas, desafíos y perspectivas", en BAZÁN, Víctor y NASH, Claudio (Eds.), Justicia constitucional y derechos fundamentales. El control de convencionalidad 2011 (Santiago, Konrad Adenauer-Stiftung E. V.) pp. 17-55.

BAZÁN, Víctor (2010): "En torno al control de las inconstitucionalidades e inconvencionalidades omisivas", Anuario de Derecho Constitucional Latinoamericano, Año XVI: pp. 151-177. 
Caballero Ochoa, José Luis (2011): "La cláusula de interpretación conforme y el principio pro persona (art. $1^{\circ}$ segundo párrafo de la Constitución)", en CARBOnEll SánCHEZ, Miguel y Salazar UGarte, Pedro (Coords.), La reforma constitucional de derechos humanos: un nuevo paradigma (México, Unam) pp. 103-133.

Cançado Trindade, Antonio A. (2013): "Compliance with Judgments and Decisions The Experience of the Inter-American Court of Human Rights: a Reassessment", Revista do Instituto Brasileiro de Dereitos Humanos, Vol. 13, No 13: pp. 29-36.

Cançado Trindade, Antonio A. (2006): El Derecho Internacional de los Derechos Humanos en el siglo XXI (Santiago, Editorial Jurídica de Chile, segunda edición).

Carbonell, Miguel (s/f): "Introducción general al control de convencionalidad". Disponible en: http://biblio.juridicas.unam.mx/libros/7/3271/11.pdf. Fecha de consulta: 11 de noviembre del 2015.

Castilla, Juárez, Karlos (2016): "Control de convencionalidad interamericano: Una propuesta de orden ante diez años de incertidumbre", Revista IIDH, Vol. 64: pp. 87-125.

Castilla Juárez, Karlos (2014): "Control de convencionalidad interamericano: una mera aplicación del Derecho Internacional”, Revista Derecho del Estado, No 33: pp. 149-172.

Castilla Juárez, Karlos (2013): “¿Control interno o difuso de convencionalidad? Una mejor idea: la garantía de los tratados”, Anuario Mexicano de Derecho Internacional, vol. XIII: pp. 51-97.

Castilla JuÁrez, Karlos (2011a): "Un nuevo panorama constitucional para el derecho internacional de los derechos humanos en México", Estudios Constitucionales, Año 9, No 2: pp. 123-164.

Castilla Juárez, Karlos (2011b): "El control de convencionalidad; un nuevo debate en México a partir de la sentencia del caso Radilla Pacheco", Anuario Mexicano de Derecho Internacional, vol. XI: pp. 593-624.

Contesse, Jorge (2013): “¿La última palabra? Control de convencionalidad y posibilidades de diálogo con la Corte Interamericana de Derechos Humanos”. Disponible en: http:// www.law.yale.edu/documents/pdf/sela/SELA13_Contesse_CV_Sp_20130401.pdf. Fecha de consulta: 28 de marzo del 2016.

Contreras, Pablo (2014): "Control de convencionalidad, deferencia internacional y discreción nacional en la jurisprudencia de la Corte Interamericana de Derechos Humanos", Ius et Praxis, Año 20, No 2: pp. 235-274.

Dulitzky, Ariel E. (2015): "An Inter-American Constitutional Court? The Invention of the Conventionality Control by the Inter-American Court of Human Rights", Texas International Law Journal, vol. 50, Issue 1: pp. 45-93.

Dulitzky, Ariel E. (2014): "El impacto del control de convencionalidad. ¿Un cambio de paradigma en el sistema interamericano de derechos humanos?”, en Rivera, Julio César et al. (Dirs.), Tratado de los derechos constitucionales (Buenos Aires, Abeledo Perrott) pp. 533-569.

Ferrer Mac-Gregor, Eduardo (2016): "El control de convencionalidad como un vehículo para el diálogo judicial entre la Corte Interamericana de Derechos Humanos y los tribunales de América”, Anuario de Derecho Constitucional Latinoamericano, Año XXII: pp. 337-356. 
Ferrer Mac-Gregor, Eduardo (2014): "Control de convencionalidad (sede interna)", en Ferrer Mac-Gregor, Eduardo et al. (Coords.), Diccionario de Derecho Procesal Constitucional y Convencional (México, UNAM, segunda edición) pp. 236-240.

Ferrer Mac-Gregor, Eduardo (2013): "Eficacia de la sentencia interamericana y la cosa juzgada internacional: vinculación directa hacia las partes (res judicata) e indirecta hacia los estados parte de la Convención Americana (res interpretata) (sobre el cumplimiento del caso Gelman vs Uruguay)", Estudios Constitucionales, Año 11, No 2: pp. 641-693.

Ferrer Mac-Gregor, Eduardo (2011): "Interpretación conforme y control difuso de convencionalidad. El nuevo paradigma para el juez mexicano", en CArbonell, Miguel y Salazar, Pedro (Eds.), Derechos humanos; un nuevo modelo constitucional (México, UNAM) pp. 339-429.

Ferrer Mac-Gregor, Eduardo (2010): "El control difuso de convencionalidad en el Estado constitucional". Disponible en: http://biblio.juridicas.unam.mx/libros/6/2873/9. pdf. Fecha de consulta: 12 septiembre del 2016.

Furfaro, Lautaro (2017): "Las ataduras de Ulises se aflojan: el pronunciamiento de la CSJN frente al caso 'Fontevecchia' de la Corte IDH”, Pensar en Derecho, Universidad de Buenos Aires, No 10, Año 5: pp. 37-79.

García Pino, Gonzalo y Contreras Vásquez, Pablo (2014): Diccionario Constitucional Chileno (Santiago, Cuadernos del Tribunal Constitucional No 55 ).

García Ramírez, Sergio (2015): "The Relationship between Inter-American Jurisdiction and States (National Systems): Some Pertinent Questions", Notre Dame Journal of International \& Comparative Law, Vol. 5, Issue 1: pp. 115-151.

García Ramírez, Sergio (2011): "El control judicial interno de convencionalidad”, IUS, Revista del Instituto de Ciencias Jurídicas de Puebla, Año V, No 28: pp. 123-159.

HaWkins, Darren y JaCoby, Wade (2010): "Partial compliance: a comparison of the European and Inter-American Courts of Human Rights", Journal of International Law and International Relations, Vol. 6 No 1, pp: 35-85.

Henríquez ViÑas, Miriam (2014): "La polisemia del control de convencionalidad interno", International Law, Revista Colombiana de Derecho Internacional, vol. 24: pp. 113341.

Henríquez Viñas, Miriam (2009): Las fuentes formales del Derecho (Santiago, LegalPublishing).

Hitters, Juan Carlos (2013): "Un avance en el control de convencionalidad. (El efecto "erga omnes" de las sentencias de la Corte Interamericana)", Estudios Constitucionales, Año 11, No 2: pp. 695-710.

Hitters, Juan Carlos (2012): "El control de convencionalidad y el cumplimiento de las sentencias de la Corte Interamericana", Estudios Constitucionales, Año 10, No 2: pp. 535-574.

Hitters, Juan Carlos (2009): "Control de constitucionalidad y control de convencionalidad. Comparación (Criterios fijados por la Corte Interamericana de Derechos Humanos)", Estudios Constitucionales, Año 7, No 2: pp. 109-128.

Hitters, Juan Carlos (2008): “¿Son vinculantes los pronunciamientos de la Comisión y de la Corte Interamericana de Derechos Humanos? (control de constitucionalidad y con- 
vencionalidad)", Revista Iberoamericana de Derecho Procesal Constitucional, No 10, juliodiciembre: pp. 131-156.

IbÁŃEZ Rivas, Juana María (2012): "Control de convencionalidad: precisiones para su aplicación desde la jurisprudencia de la Corte Interamericana de Derechos Humanos", Anuario de Derechos Humanos, vol. 8: pp. 103-113.

Malarino, Ezequiel (2011): "Activismo judicial, punitivización y nacionalización. Tendencias antidemocráticas y antiliberales de la Corte Interamericana de Derechos Humanos", en Grupo Latinoamericano de Estudios sobre Derecho Penal Internacional, Sistema Interamericano de Protección de los Derechos Humanos y Derecho Penal Internacional (Montevideo, Konrad-Adenauer-Stiftung e. V.) pp. 25-61.

Meier García, Eduardo (2011): "Nacionalismo constitucional y Derecho Internacional de los Derechos Humanos”, Estudios Constitucionales, Año 9, No 2: pp. 329-376.

Mejía Lemos, Diego Germán (2014): "On the "Control de Convencionalidad“ Doctrine: a Critical Appraisal of the Inter-American Court of Human Rights' Relevant Case Law", Anuario Mexicano de Derecho Internacional, vol. XIV: pp. 117-151.

Nash Rojas, Claudio (2013): “Control de convencionalidad. Precisiones conceptuales u desafíos a la luz de la jurisprudencia de la Corte Interamericana de Derechos Humanos", Anuario de Derecho Constitucional Latinoamericano, Año XIX: pp. 489-509.

Nogueira Alcalá, Humberto (2012a): "El uso del derecho convencional internacional de los derechos humanos en la jurisprudencia del Tribunal Constitucional chileno en el período 2006-2010", Revista Chilena de Derecho, vol. 39, No 1: pp. 149-187.

Nogueira Alcalá, Humberto (2012b): "Los desafíos del control de convencionalidad del corpus iuris interamericano para las jurisdicciones nacionales", Boletín Mexicano de Derecho Comparado, Nueva serie, año XLV, No 135: pp. 1167-1220.

Nogueira Alcalá, Humberto (2012c): "Diálogo interjurisdiccional, control de convencionalidad y jurisprudencia del Tribunal Constitucional en el período 2006-2011”, Estudios Constitucionales, Año 10, No 2: pp. 57-140.

Nogueira Alcalá, Humberto (2013a): "El uso del derecho y jurisprudencia constitucional extranjera de tribunales internacionales no vinculantes por el Tribunal Constitucional chileno en el período 2006-2011", Estudios Constitucionales, Año 11, No 1: pp. 221274.

Nogueira Alcalá, Humberto (2013b): "Diálogo interjurisdiccional y control de convencionalidad entre los tribunales nacionales y la Corte Interamericana de Derechos Humanos en Chile", Anuario de Derecho Constitucional latinoamericano, Año XIX: pp. 511-553.

Nogueira Alcalá, Humberto (2013c): “El control de convencionalidad y el diálogo interjurisdiccional entre tribunales nacionales y Corte Interamericana de Derechos Humanos", Revista de Derecho Constitucional Europeo, Año 10, Núm. 19: pp. 221-270.

Núñez Poblete, Manuel (2010): "Sobre la declaración de inaplicabilidad de los tratados internacionales. Un estudio en defensa de su fundamento y legitimidad", Estudios Constitucionales, Año 8, No 2: pp. 461-464.

Olano García, Hernán Alejandro (2017): “Teoría del Control de Convencionalidad”, Estudios Constitucionales, Año 14 No 1: pp. 61-94. 
Paúl Díaz, Álvaro (2013): "La Corte Interamericana in vitro: notas sobre su proceso de toma de decisiones a propósito del Caso Artavia", Revista Derecho Público Iberoamericano, Universidad del Desarrollo, Año 1, No 2: pp. 303-345.

Pereyra Zabala, Gastón (2011): "El control de convencionalidad en el sistema interamericano de derechos humanos", Revista de Derecho, Montevideo, No 6: pp. 155-176.

SAGÜÉs, Néstor P. (2015): "Las opiniones consultivas de la Corte Interamericana, en el control de convencionalidad", Pensamiento Constitucional, No 20: pp. 275-283.

SAGÜÉs, Néstor P. (2014): "Derechos constitucionales y derechos humanos. De la Constitución Nacional a la Constitución "convencionalizada", en Nogueira AlCalÁ, Humberto (Coord.), La protección de los derechos humanos y fundamentales de acuerdo a la constitución y el Derecho Internacional de los Derechos Humanos (Santiago, Librotecnia) pp. 1523.

SAGÜÉS, Néstor P. (2010): "Obligaciones internacionales y control de convencionalidad", Estudios Constitucionales, Año 8, No 1: pp. 117-136.

SAGÜÉs, Néstor P. (2009): "El 'control de convencionalidad', en particular sobre las constituciones nacionales”, La Ley, 19/02/2009, 1. Disponible en: http://www.joseperezcorti. com.ar/Archivos/DC/Articulos/Sagues_Control_de_Convencionalidad_LL_2009.pdf. Fecha de consulta: 03 de octubre del 2016.

SAGÜÉS, Néstor P. (2003): "Las relaciones entre los tribunales internacionales y los tribunales nacionales en materia de derechos humanos. Experiencias en Latinoamérica”, Ius et Praxis, Año 9, No 1: pp. 205-221.

SAGÜÉS, Néstor P. (s/f a): "El "Control de convencionalidad" como instrumento para la elaboración de un ius commune interamericano”. Disponible en: http://biblio.juridicas. unam.mx/libros/6/2895/15.pdf. Fecha de consulta: 15 de marzo del 2016.

SAGÜÉs, Néstor P. (s/f b): "El 'control de convencionalidad' en el sistema interamericano y sus anticipos en el ámbito de los derechos económico-sociales. Concordancias y diferencias con el sistema europeo". Disponible en: http://biblio.juridicas.unam.mx/ libros/7/3063/16.pdf. Fecha de consulta: 5 de diciembre del 2016.

Salgado Ledesma, Eréndira (2012): "La probable inejecución de las sentencias de la Corte Interamericana de Derechos Humanos", Revista Mexicana de Derecho Constitucional, Núm. 26, junio-diciembre: pp. 221-260.

Silva Аввотт, Max (2016): "Control de convencionalidad y jueces locales: un planteamiento defectuoso", Estudios Constitucionales, año 14, No 2: pp. 101-142.

TAPIA VAldÉs, Jorge (2008): "Poder constituyente irregular: los límites metajurídicos del poder constituyente originario", Estudios Constitucionales, Año 6, No 2: pp. 133-134.

Vio Grossi, Eduardo (2015): "Jurisprudencia de la Corte Interamericana de Derechos Humanos: ¿del control de convencionalidad a la supranacionalidad?", Anuario de Derecho Constitucional Latinoamericano, Año XXI: pp. 93-112. 


\section{JURISPRUDENCIA CITADA}

Corte Interamericana de Derechos Humanos. Casos Contenciosos: http://www.corteidh.or.cr/cf/Jurisprudencia2/busqueda_casos_contenciosos.cfm?lang=es. Fecha de última consulta: 30 de mayo de 2016.

Corte Interamericana de Derechos Humanos. Medidas Provisionales: http://www.corteidh.or.cr/cf/Jurisprudencia2/busqueda_medidas_provisionales.cfm?lang=es. Fecha de última consulta: 30 de mayo de 2016.

Corte Interamericana de Derechos Humanos. Supervisiones de Cumplimiento: http://www.corteidh.or.cr/cf/Jurisprudencia2/busqueda_supervision_cumplimiento. cfm?lang=es. Fecha de última consulta: 30 de mayo de 2016.

\section{ANEXO I}

A continuación, se enumeran cronológicamente los casos en que la Corte Interamericana de Derechos Humanos alude a la doctrina del control de convencionalidad en sus sentencias de fondo hasta diciembre de 2017 y si corresponde, también en alguna sentencia de interpretación o en una supervisión de cumplimiento (S.C.). Se señalan los párrafos en que ello ocurre y, además, el estado actual de la causa (C. Total, C. Parcial, Incumplida y Pendiente), indicándose en las tres primeras oportunidades en una nota a pie de página, los Puntos Resolutivos (“Pto. Resol.") o Puntos Declarativos (“Pto. Decl.") de las S.C. de cada caso que fundamentan esta calificación. En las causas Pendientes no existe nota a pie de página, pues todavía no se han dictado S.C. que indiquen el real estado del caso, que, en el fondo, puede estar Incumplido o con C. Parcial. Debe advertirse que casi todas las S.C. que se mencionan en las notas a pie de página son distintas a las indicadas en la presente lista, que solo incluyen las que hacen alusión al control de convencionalidad. Todas han sido extraídas de la página web de la Corte Interamericana (http://www.corteidh.or.cr/cf/ Jurisprudencia2/busqueda_supervision_cumplimiento.cfm?lang=es) y se puede acceder a ellas con el nombre de la sentencia definitiva que aquí se indica y el año, que se señala en la nota a pie de página. Finalmente, cuando se indica la fecha exacta de una S.C. ello se debe a que existen dos en ese año respecto de la misma causa.

Almonacid Arellano y otros vs Chile. 26 de septiembre de 2006, Serie C No 154, párr. 124 a 126, C. Parcial ${ }^{73}$.

Trabajadores Cesados del Congreso (Aguado Alfaro y otros) vs Perú. 24 de noviembre de 2006, Serie C No 158, párr. 128, Incumplida ${ }^{74}$.

La Cantuta vs Perú. 29 de noviembre de 2006, Serie C No 162, párr. 173, Incumplida ${ }^{75}$.

73 S.C. (2010) Ptos. Decl. 1 y 2.

74 S.C. (20.11.2009) Pto. Decl. 1. S.C. (2010) Pto. Decl. 1.

75 S.C. (2009) Ptos. Decl. 1, 2 y 3. 
Boyce y otros vs BARBADOs. 20 de noviembre de 2007, Serie C No 169, párr. 78, C. Par$\operatorname{cial}^{76}$.

Chaparro Álvarez y Lapo Íñiguez vs Ecuador. 21 de noviembre de 2007, Serie C No 170, párr. 268, C. Parcial ${ }^{77}$.

Heliodoro Portugal vs Panamá. 12 de agosto de 2008, Serie C No 186, párr. 180, C. Parcial $^{78}$

Radilla Pacheco vs México. 23 de noviembre de 2009, Serie C No 209, párr. 339 y nota 321, C. Parcial ${ }^{79}$.

S.C. 28 de junio de 2012, párr. 17.

S.C. 14 de mayo de 2013, párr. 5, 19, 26 y nota 17.

S.C. 17 de abril de 2015, párr. 16 y 21.

Manuel Cepeda Vargas vs Colombia. 26 de mayo de 2010, Serie C No 213, nota 307 (párr. 208), C. Parcial ${ }^{80}$.

Comunidad Indígena Xákmok Kásek vs Paraguay. 24 de agosto de 2010, Serie C No 214, párr. 311, C. Parcial ${ }^{81}$.

FERNÁNDEZ ORTEGA y otros vs MÉXICo. 30 de agosto de 2010, Serie C No 215, párr. 336 y 337, C. Parcial ${ }^{82}$.

Interpretación de la Sentencia de Fondo. 15 de mayo de 2011, Serie C No 224, párr. 19.

S.C. 17 de abril de 2015, párr. 16 y 21.

Rosendo Cantú y otra vs México. 31 de agosto de 2010, Serie C No 216, párr. 219 y 220, C. Parcial ${ }^{83}$.

Interpretación de la Sentencia de Fondo. 15 de mayo de 2011, Serie C No 225, párr. 19.

S.C. 17 de abril de 2015, párr. 16 y 21.

Ibsen Cardenas e IbSen Peña vs Bolivia. 1 de septiembre de 2010, Serie C No 217, párr. 202, C. Parcial ${ }^{84}$.

VÉLez Loor vs PANAMÁ. 23 de noviembre de 2010, Serie C No 218, párr. 287, C. Parcial ${ }^{85}$.

Gomes Lund y otros ("GuerRilha do ARAGUaia”) vs Brasil. 24 de noviembre de 2010, Serie

C No 219, párr. 49, 176 y 177, C. Parcial ${ }^{86}$.

S.C. 17 de octubre de 2014, párr. 16, 18 y 19.

76 S.C. (2011) Ptos. Decl. 1, 2 y 3.

77 S.C. (2009) Pto. Decl. 1; S.C. (2010) Pto. Decl. 1; S.C. 2015; Pto. Decl. 1, S.C. 2016; Ptos. Decl. 1 y 2.

78 S.C. (25.05.2010) Pto. Decl. 1; S.C. (2012) Ptos. Decl. 1 y 3; S.C. (2017) Ptos. Resol. 1 a 3.

79 S.C. (19.05.2011) Ptos. Decl. 1 y 2; S.C. (01.12.2011) Pto. Decl. 1; S.C. (2012) Pto. Decl. 1; S.C. (2013) Ptos. Resol. 1 y 2; S.C. (2015) Pto. Resol. 1.

80 S.C. (2011) Ptos. Decl. 1 y 2.

81 S.C. (2017) Ptos. Resol. 1, 3c y 4.

82 S.C. (2014) Ptos. Resol. 1 y 2; S.C. (2015) Ptos. Resol. 1 y 2.

83 S.C. (2014) Ptos. Resol. 1 y 2; S.C. (2015) Ptos. Resol. 1 y 2.

84 S.C. (2013) Ptos. Decl. 1 y 2.

85 S.C. (2013) Ptos. Decl. 1 y 2.

86 S.C. (2014) Ptos. Decl. 1, 3, 4, 5 y 6. 
Cabrera García y Montiel Flores vs México. 26 de noviembre de 2010, Serie C No 220, párr. 21 y 225 a 233, C. Parcial ${ }^{87}$.

S.C. 21 de agosto de 2013, párr. 5, 29 (y nota 16) y 37 (y nota 21).

S.C. 17 de abril de 2015, párr. 16 y 21.

Gelman vs URUGUAY. 24 de febrero de 2011, Serie C No 221, párr. 193 y 239, C. Parcial ${ }^{88}$.

S.C. 20 de marzo de 2013, párr. 37, 57 a 90 y 102.

Chocrón Chocrón vs Venezuela. 1 de julio de 2011, Serie C No 227, párr. 164 a 172, Incumplida ${ }^{89}$.

López MeNdoza vs VeneZuela. 1 de septiembre de 2011, Serie C No 233, párr. 226 a 228, Incumplida ${ }^{90}$.

Fontevecchia y D`Amico vs Argentina. 29 de noviembre de 2011, Serie C No 238, párr. 93, Incumplida ${ }^{91}$.

S.C. 18 de octubre de 2017. párr. 25.

Atala Riffo y NiÑas vs Chile. 24 de febrero de 2012, Serie C No 239, párr. 282 a 284, C. Parcial $^{92}$.

S.C. 10 de febrero de 2017, párr. 20 (nota 27) y 25 (nota 36).

Furlan y Familiares vs ARgentina. 31 de agosto de 2012, Serie C No 246, párr. 303 a 305, Pendiente.

MASACRES DE Río NegRo vs Guatemala. 4 de septiembre de 2012, Serie C No 250, párr. 262, Incumplida ${ }^{93}$.

S.C. 21 de agosto de 2014, párr. 16 y 17.

Masacres de EL Mozote Y LUGARES ALEDAÑos VS EL SALVADOR. 25 de octubre de 2012, Serie C No 252, párr. 318, C. Parcial ${ }^{94}$.

Gudiel Álvarez y otros (Diario Militar) vs Guatemala. 20 de noviembre de 2012, Serie C No 253, párr. 330, Incumplida ${ }^{95}$.

S.C. 21 de agosto de 2014, párr. 16 y 17.

Masacre de Santo Domingo vs Colombia. 30 de noviembre de 2012, Serie C No 259, párr. 142, Pendiente.

Mendoza y otros vs ARgentina. 14 de mayo de 2013, Serie C No 260, párr. 221, 257, 323 y 332 , Pendiente.

Familia Pacheco Tineo vs Bolivia. 25 de noviembre de 2013, Serie C No 272, párr. 234, C. Total $^{96}$.

87 S.C. (2014) Ptos. Resol. 1 y 2; S.C. (2015) Ptos. Resol. 1 y 2.

88 S.C. (2013) Ptos. Decl. 1, 2, 3 y 4.

89 S.C. (2015) Pto. Decl. 1; S.C. (2016) Ptos. Decl. 1, 2 y 3.

$90 \quad$ S.C. (2015) Ptos. Decl. 1 y 2.

91 S.C. (2015) Ptos. Decl. 1 y 2; S.C. (2016) Ptos. Decl. 1 y 2; S.C. (2017) párr. 35-37, 40-42 y Ptos. Resol. 1 a 3.

92 S.C. (2013) Ptos. Resol. 1 y 2 y S.C. (2017) Ptos. Resol. 1 a 3.

93 S.C. (2014) Pto. Resol. 1; S.C. (2017) Ptos. Resol. 1 a 4.

94 S.C. (2017) párr. 12 y Ptos. Resol. 1 y 2.

95 S.C. (2016) Pto. Resol. 1.

96 S.C. (2015) Ptos. Resol. 1 a 5. 
García Cruz y Sanchez Silvestre vs México. 26 de noviembre de 2013, Serie C No 273, Nota 76 (párr. 59) y párr. 91, C. Parcial ${ }^{97}$.

J. vs PeRÚ. 27 de noviembre de 2013, Serie C No 275, párr. 407, Pendiente.

Liakat Ali Alibux vs Suriname. 30 de enero de 2014, Serie C No 276, párr. 124 a 125 y 151, Pendiente.

Norín CATRIMÁN Y OtRos (DiRIGENTES, MIEMBRos Y ACTIVISTA DEL PUEBLO INDÍGENA MAPUCHE) vs ChILE. 29 de mayo de 2014, Serie C No 279, párr. 436, 461 y 464, Pendiente.

Personas dominicanas y hattianas expulsadas vs República Dominicana. 28 de agosto de 2014, Serie C No 282, párr. 311, 453 y 471, Pendiente.

RochaC HeRnANDEZ y otros vs El SALVADOR. 14 de octubre de 2014, Serie C No 285, párr. 213, Incumplida ${ }^{98}$.

S.C. 9 de febrero de 2017, párr. $17 \mathrm{~d}$.

López Lone Y otros vs Honduras. 5 de octubre de 2015, Serie C No 302, párr. 307, C. Parcial ${ }^{99}$.

Comunidad Gariffuna de Punta Piedra y sus Miembros vs Honduras. 8 de octubre de 2015, Serie C No 304, párr. 211, 255 y 346, Pendiente.

Comunidad Garífuna Triunfo de la CRUZ y sus Miembros vs Honduras. 8 de octubre de 2015, Serie C No 305, párr. 267, Pendiente.

GARCÍA IBARRA Y OTROS VS ECUADOR. 17 de noviembre de 2015, Serie C No 306, párr. 103 y nota 125 , C. Total ${ }^{100}$.

Tenorio Roca y otros vs Perú. 22 de junio de 2016, Serie C No 314, párr. 230 y 231, Pendiente.

Miembros de la Aldea Chichupac y comunidades veCinas del Municipio de Rabinal vs Guatemala. 30 de noviembre de 2016, Serie C No 328, párr. 207, Pendiente.

Andrade Salmón vs Bolivia. 1 de diciembre de 2016, Serie C No 330, párr. 93 (y nota 156), 94 y 102, Pendiente.

Vereda La Esperanza vs Colombia. 31 de agosto de 2017. Serie C No 341, párr. 261. Pendiente.

a. Pollo Rivera y Otros vs Perú. Interpretación de la Sentencia de Fondo. 25 de mayo de 2017, Serie C No 335, párr. 2, 13 y 15, Pendiente (en esta causa no se alude al control de convencionalidad en la sentencia de fondo).

\section{ANEXO II}

A continuación, se enumeran los casos en que la Corte Interamericana de Derechos Humanos alude a la doctrina del control de convencionalidad hasta diciembre de 2017 no en sus sentencias definitivas, sino por regla general, en alguna S.C. posterior, en razón de tratarse de causas falladas con antelación a la aparición de esta doctrina. Por eso la cronolo-

\footnotetext{
$97 \quad$ S.C. (2016) Ptos. Resol. 1 a 5.

98 S.C. (2017) párr. 3 a 5 y Ptos. Resol. 1 a 3.

99 S.C. (2017) Ptos. Resol. 1 a 6.

100 S.C. (2017) Ptos. Resol. 1 a 5.
} 
gía de este anexo depende de la fecha de esta S.C., no de la fecha de la sentencia definitiva. Se señalan los párrafos en que se alude a este control y, además, el estado actual de la causa (C. Total, C. Parcial e Incumplida), indicándose en una nota a pie de página los Puntos Resolutivos ("Pto. Resol.") o Puntos Declarativos ("Pto. Decl.") de las S.C. y eventualmente, de medidas provisionales (M.P.) de cada caso que fundamentan esta calificación. Debe advertirse que la mayoría de las S.C. que se mencionan en las notas a pie de página son distintas a las indicadas en la presente lista, que solo incluye las que hacen alusión al control de convencionalidad, pero todas han sido extraídas de la página web de la Corte (http:// www.corteidh.or.cr/cf/Jurisprudencia2/busqueda_supervision_cumplimiento.cfm?lang=es) y se puede acceder a ellas con el nombre de la sentencia definitiva que aquí se indica y el año, que se señala en la nota a pie de página. Cuando se menciona la fecha exacta de una S.C. ello se debe a que existen dos en ese año respecto de la misma causa. Finalmente, debido a su antigüedad, aquí no existen causas Pendientes, como en el anexo I.

Fermín Ramírez vs Guatemala. 20 de junio de 2005, Serie C No 126, C. Parcial ${ }^{101}$.

S.C. 9 de mayo de 2008, párr. 63.

RaXCACó Reyes vs Guatemala. 15 de septiembre de 2005, Serie C No 133, C. Parcial ${ }^{102}$.

S.C. 9 de mayo de 2008, párr. 63.

Zambrano Vélez y otros vs Ecuador. 4 de julio de 2007, Serie C No 166, C. Parcial ${ }^{103}$.

S.C. 21 de septiembre de 2009, párr. 42.

“Cinco Pensionistas" vs Perú. 28 de febrero de 2003, Serie C No 98, C. Parcial ${ }^{104}$.

S.C. 24 de noviembre de 2009, párr. 35.

BÁmACA VELASQUeZ vs GUATEMALA. 25 de noviembre de 2000, Serie C No 70, Incumplida ${ }^{105}$.

S.C. 18 de noviembre de 2010, párr. 33 .

Supervisión CONJunta de 11 Casos vs Guatemala. S.C. 21 de agosto de 2014, párr. 17.

12 Casos Guatemaltecos vs Guatemala. S.C. 24 de noviembre de 2015, párr. 26 y 142.

Wong Ho Wing vs Perú. 30 de junio de 2015, Serie C No 297, C. Parcial ${ }^{106}$.

Medidas Provisionales respecto de la República del Perú. 10 de octubre de 2011, párr. 11.

Castillo Petruzzi y otros vs Perú. 30 de mayo de 1999, Serie C No 52, C. Total ${ }^{107}$.

S.C. 1 de julio de 2011, párr. 20.

Loayza Tamayo vs Perú. 17 de septiembre de 1997, Serie C No 33, C. Parcial ${ }^{108}$.

S.C. 1 de julio de 2011, párr. 35.

\footnotetext{
101 S.C. (2006) Ptos. Decl. 1 y 2; S.C. (9.3.2008) Ptos. Decl. 1 y 2; S.C. (28.3.2008) párr. 67 a 69.

102 S.C. (28.3.2008) párr. 67 a 69; S.C. ((9.9.2008) Ptos. Decl. 3, 4 y 5.

103 S.C. (22.5.2009) Pto. Resol. 1; S.C. (21.9.2009) Ptos. Decl. 1, 2 y 3; S.C. (2010) Ptos. Decl. 1 y 2; S.C.

(2016) Ptos. Resol. 1 y 2.

104 S.C. (2008) párr. 10; S.C. (2016) Ptos. Resol. 1 a 5; S.C. (2009) Pto. Resol. 1.

105 S.C. (2003) Pto. Decl. 1; Supervisión Conjunta 11 Casos vs Guatemala (2014) Pto. Resol. 1; 12 Casos Guatemaltecos vs Guatemala (2015) párr. 20, 63 a 72, 126, 170 y 175.

106 S.C. (2016) Ptos. Resol. 1, 2 y 3.

107 S.C. (2016) Ptos. Resol. 1 al 5.

108 S.C. (2001) párr. 13, Consid. 4 y Pto. Resol. 1; S.C. (2002) Consid. 6; S.C. (2005) Pto. Decl. 1; S.C. (2011) Ptos. Decl. 1 y 2.
} 
Apitz Barbera y otros (“Corte Primera de lo Contencioso Administrativo”) vs Venezuela. 5 de agosto de 2008, Serie C No 182, Incumplida ${ }^{109}$.

S.C. 23 de noviembre de 2012, párr. 26 a 29.

Barrios Altos vs Perú. 14 de marzo de 2001, Serie C No 75, C. Parcial ${ }^{110}$.

S.C. 7 de septiembre de 2012, párr. 9, 24 y 35.

Lori Berenson MejÍa vs Perú. 25 de noviembre de 2004, Serie C No 119, C. Total ${ }^{111}$.

S.C. 20 de junio de 2012, párr. 18.

Anzualdo Castro vs Perú. 22 de septiembre de 2009, Serie C No 202, Incumplida ${ }^{112}$

S.C. 21 de agosto de 2013, párr. 24 a 26.

Castañeda Gutman vs México. 6 de agosto de 2008, Serie C No 184, C. Total ${ }^{113}$.

S.C. 28 de agosto de 2013, párr. 14, 21 a 27 y 30.

GonzÁleZ y otras ("CAMPO ALGODONERO") VS MÉXICO. 16 de noviembre de 2009, Serie C No 205, C. Parcial ${ }^{114}$.

S.C. 21 de mayo de 2013, párr. 78.

Masacres de Ituango vs Colombia. 1 de julio de 2006, Serie C No 148, C. Parcial ${ }^{115}$.

S.C. 21 de mayo de 2013, párr. 27, 29 y 30.

Blake vs Guatemala. 24 de enero de 998, Serie C No 36, C. Parcial ${ }^{116}$.

SuperVisión CONJunta de 11 casos vs GuATEMala. S.C. 21 de agosto de 2014, párr. 17.

12 Casos Guatemaltecos vs Guatemala. S.C. 24 de noviembre de 2015, párr. 26 y 142.

"Niños de LA Calle" (Villagrán Morales y otros) vs Guatemala. 19 de noviembre de 1999, Serie C No 63, Incumplida ${ }^{117}$.

SuperVisión CONJUNTA DE 11 CASOS vs GuATEMaLa. S.C. 21 de agosto de 2014, párr. 17.

12 Casos Guatemaltecos vs Guatemala. S.C. 24 de noviembre de 2015, párr. 26 y 142.

Myrna Mack Chang vs Guatemala. 25 de noviembre de 2003, Serie C No 101, C. Parcial $^{118}$.

SuPERVISIÓN CONJUNTA DE 11 CASOS vs GUATEMALA. S.C. 21 de agosto de 2014, párr. 17. 12 Casos Guatemaltecos vs Guatemala. S.C. 24 de noviembre de 2015, párr. 26 y 142. Maritza URRutia vs Guatemala. 27 de noviembre de 2003, Serie C No 103, Incumplida ${ }^{119}$.

\footnotetext{
109 S.C. (2012) Ptos. Decl. 1 y 2.

110 S.C. (2003) Ptos. Decl. 3 y 4; S.C. (2004) Pto. Decl. 1; S.C. (2005) Pto. Decl. 1; S.C. (2008) Pto. Decl. 1; S.C. (2012) Ptos. Decl. 1 y 2.

111 S.C. (2012) Ptos. Resol. 1 al 4.

112 S.C. (2013) Ptos. Resol. 1, 2 y 3.

113 S.C. (2013) Ptos. Resol. 1 al 5.

114 S.C. (2013) Ptos. Resol. 1 y 2.

115 S.C. (2009) Pto. Decl. 1; S.C. (2011) Ptos. Decl. 1 y 2; S.C. (2013) Ptos. Resol. 1, 2 y 3.

116 S.C. (2003) Pto. Decl. 1; 12 Casos Guatemaltecos vs Guatemala (2015) párr. 20, 46 a 52, 126, 170, 174 y 175.

117 S.C. (2003) Pto. Decl. 1; S.C. (2005) Pto. Decl. 1; Supervisión Conjunta 11 Casos vs Guatemala (2014) Pto. Resol. 1; 12 Casos Guatemaltecos vs Guatemala (2015) párr. 20, 56 a 62, 126, 170, 174 y 175.

118 S.C. (2005) Ptos. Decl. 1, 2 y 3; S.C. (2007) párr. 15 y Ptos. Decl. 1 y 2; S.C. (16.11.2009) párr. 13 y Pto. Decl. 1; 12 Casos Guatemaltecos vs Guatemala (2015) párr. 20, 73 a 75, 126 y 173.

119 S.C. (2005) Pto. Decl. 1; Supervisión Conjunta 11 Casos vs Guatemala (2014) Pto. Resol. 1; 12 Casos GuatemaLtecos vs GuATEMaLA (2015) párr. 20, 76 a 81, 126, 170, 174 y 175.
} 
Supervisión CONJUNTA de 11 CASOS vs GuATEMala. S.C. 21 de agosto de 2014, párr. 17. 12 Casos Guatemaltecos vs Guatemala. S.C. 24 de noviembre de 2015, párr. 26 y 142. Masacre Plan de Sanchez vs Guatemala. 29 de abril de 2004, Serie C No 105, C. Parcial $^{120}$.

SuperVisión CONJUNTA de 11 CASOS vs Guatemala. S.C. 21 de agosto de 2014, párr. 17. 12 Casos Guatemaltecos vs Guatemala. S.C. 24 de noviembre de 2015, párr. 26 y 142. Molina Theissen vs Guatemala. 4 de mayo de 2004, Serie C No 106, Incumplida ${ }^{121}$. Supervisión CONJunta de 11 casos vs Guatemala. S.C. 21 de agosto de 2014, párr. 17. 12 Casos Guatemaltecos vs Guatemala. S.C. 24 de noviembre de 2015, párr. 26 y 142. Carpio Nicolle y otros vs Guatemala. 22 de noviembre de 2004, Serie C No 117, C. Parcial $^{122}$.

SuperVisión CONJUNTA de 11 CASOS vs Guatemala. S.C. 21 de agosto de 2014, párr. 17. 12 Casos Guatemaltecos vs Guatemala. S.C. 24 de noviembre de 2015, párr. 26 y 142. Tiu Tojín vs Guatemala. 26 de noviembre de 2008, Serie C No 190, Incumplida ${ }^{123}$. Supervisión CONJunta de 11 Casos vs Guatemala. S.C. 21 de agosto de 2014, párr. 17. 12 Casos Guatemaltecos vs Guatemala. S.C. 24 de noviembre de 2015, párr. 26 y 142. Masacre de las Dos ERres vs Guatemala. 24 de noviembre de 2009, Serie C No 211, C. Parcial $^{124}$.

SuperVisión CONJUNTA de 11 CASOS vs Guatemala. S.C. 21 de agosto de 2014, párr. 17. 12 Casos Guatemaltecos vs Guatemala. S.C. 24 de noviembre de 2015, párr. 26 y 142. Chitay Nech y otros vs Guatemala. 25 de mayo de 2010, Serie C No 212, Incumplida ${ }^{125}$. Supervisión Conjunta de 11 casos vs Guatemala. S.C. 21 de agosto de 2014, párr. 17. 12 Casos Guatemaltecos vs Guatemala. S.C. 24 de noviembre de 2015, párr. 26 y 142. "Panel Blanca" (Paniagua Morales y otros) vs Guatemala. 8 de marzo de 1998, Serie C No 37, Incumplida ${ }^{126}$. 12 Casos Guatemaltecos vs Guatemala. S.C. 24 de noviembre de 2015, párr. 26 y 142.

120 S.C. (2007) Ptos. Resol. 1 y 2; S.C. (2008) S.C. (2009) Ptos. Decl. 1 y 2; Ptos. Decl. 1 y 2; S.C. (2011) Ptos. Decl. 1 y 2; 12 Casos Guatemaltecos vs Guatemala (2015) párr. 20, 90 a 94, 126, 170, 174 y 175.; S.C. (2017) Ptos. Resol. 1 a 4.

121 S.C. (2007) Pto. Decl. 1; Supervisión Conjunta 11 Casos vs Guatemala (2014) Pto. Resol. 1; 12 Casos Guatemaltecos vs GuATEMaLA (2015) párr. 20, 82 a 89, 126, 170, 174 y 175.

122 S.C. (2007) Ptos. Decl. 1 y 2; S.C. (2009) Pto. Decl. 1; 12 Casos Guatemaltecos vs Guatemala (2015) párr. 20, 95 a 100, 126, 170, 174 y 175.

123 S.C. (2011) Pto. Decl. 1; Supervisión Conjunta 11 Casos vs Guatemala (2014) Pto. Resol. 1; 12 Casos Guatemaltecos vs Guatemala (2015) párr. 20, 101 a 107, 126, 170, 174 y 175.

124 S.C. (2011) Ptos. Decl. 1 y 2; S.C. (2012) Pto. Decl. 1; 12 Casos Guatemaltecos vs Guatemala (2015) párr. 20, 108 a 114, 126, 170, 174 y 175.

125 S.C. (2011) Ptos. Decl. 1 y 2; S.C (2012) Pto. Decl. 1; Supervisión Conjunta 11 Casos vs Guatemala (2014) Pto. Resol. 1; 12 Casos Guatemaltecos vs Guatemala (2015) párr. 20, 115 a 121, 126, 170, 174 y 175. 126 S.C. (2003) Consid. 7 y Pto. Resol. 3; S.C. (27.11.2007) Ptos. Decl. 1 y 2; 12 Casos Guatemaltecos vs GUATEMALA (2015) párr. 20, 53 a 56, 126, 170, 174 y 175. 